\title{
Clay: New Opportunities for Tissue Regeneration and Biomaterial Design
}

\author{
Jonathan I. Dawson* and Richard O. C. Oreffo*
}

Seminal recent studies that have shed new light on the remarkable properties of clay interactions suggest unexplored opportunities for biomaterial design and regenerative medicine. Here, recent conceptual and technological developments in the science of clay interactions with biomolecules, polymers, and cells are examined, focusing on the implications for tissue engineering and regenerative strategies. Pioneering studies demonstrating the utility of clay for drug-delivery and scaffold design are reviewed and areas for future research and development highlighted.

\section{Introduction}

Recent reviews of the tissue engineering/regenerative medicine (TERM) field have increasingly emphasized the decisive contribution of the tissue engineering matrix in harnessing the regenerative potential of stem and progenitor cells. ${ }^{[1-6]}$ Whereas previously, distinctions were drawn between "inductive" growth factors and "conductive" scaffolds, technological developments, predominantly in biomaterial design and testing, have made such demarcations increasingly hard to maintain. The dynamic influence of the matrix in controling the spatio-temporal distribution of biochemical signals, ${ }^{[7]}$ the metabolic significance of matrix components, diffusive properties and degradation rate, and products, ${ }^{[3,6]}$ the instructive role of transmitted mechanical forces, ${ }^{[8]}$ and the still surprising impact that micro- and nanotopographical features have on cell behavior, ${ }^{[2,9,10]}$ all point to a significance far beyond the conventional and indeed vital conductive role the scaffold fulfills as cell delivery vehicle, and three-dimensional support structure.

This expanding remit for the tissue engineering matrix is daunting, yet while considerable challenges still remain, the concurrent expansion of scaffold technology provides a wealth of approaches to addressing this complexity. Indeed, the expanding catalogue of scaffold materials and technologies, as well as constituting a response to pre-defined cellular and clinical design constraints, ${ }^{[11]}$ has itself generated new and unforeseen insights into the diverse role of the cell matrix in tissue development, regeneration, and repair with significant therapeutic implications.

\author{
Dr. J. I. Dawson, Prof. R. O. C. Oreffo \\ Institute of Developmental Sciences \\ University of Southampton \\ Southampton, SO16 6YD, UK \\ E-mail: jid@soton.ac.uk; roco@soton.ac.uk
}

DOI: 10.1002/adma.201301034
There are vistas of opportunity in the materials science field that are only starting to be explored for regenerative applications. The focus of this review provides one such example. Recent studies investigating, for the first time, clay nanoparticles for cell-based regenerative strategies suggest the striking potential of clay minerals to provide new opportunities for biomaterial design. The well-established utility of clay nanoparticles to interact with drugs and other biological molecules for controlled delivery, and their ability to interact with polymers to enhance mechanical properties as seen in the development of polymer-clay nanocomposites are both of profound relevance to TERM. However, to date, clay minerals are only beginning to be investigated in the development of biomaterials. A literature search of experimental studies investigating clay with stated reference to TERM as an application, uncovered less than 100 citations prior to 2013, and only 31 studies have assessed cellular responses to biomaterials incorporating clay. Furthermore, most have investigated clay minerals with a view to the mechanical-benefits conferred by polymer-clay interactions, and thus the potential to harness clay biomolecule interactions for TERM strategies remains largely unexplored (Figure 1).

After briefly surveying the use of clay minerals in medicine and the underlying chemistry from which their utility derives, this Progress Report will highlight the recent advances in both the characterization and functional application of clay interactions that is driving a growing interest in this area of research. As well as reviewing the pioneering studies demonstrating enhanced stem and progenitor cell proliferation and differentiation in response to clay mineral substrates and matrices, related advances derived from the application of clay in the fields of drug-delivery and polymer nanocomposites are reviewed. Thus, this Progress Report highlights the unique opportunities afforded by clay interactions with: i) biomolecules, allowing new options for matrix protein, growth factor, and gene delivery for tissue-regeneration; ii) polymers, for the generation of claypolymer composites with enhanced mechanical properties; iii) and cells, suggesting new opportunities for functionalization of gels and surfaces for enhanced regenerative responses.

\section{Clay and Medicine: an Overview}

The use of clays for medicinal purposes extends back into prehistory. Archaeological evidence suggests application of clay to wounds and skin irritations by Homo erectus and $H$. neanderthalensis, and, in the ancient world, frequent written attestation 
is given to the ingestion of clay-containing earths to treat stomach and intestinal problems. ${ }^{[16,17]}$ Their application as active ingredients continues to the present day where clays are applied orally as antacids, gastrointestinal protectors and antidiarrhoeics, and topically in various cosmetic creams, powders, and emulsions. ${ }^{[18]}$ Furthermore, modern pharmaceutics employ clays as excipients acting variously as lubricants, diluents, flavor correctors, emulsifiers, rheological agents, and drug delivery modifiers. ${ }^{[19]}$

Clay minerals are typically layered silicate structures (phyllosilicates) that crystallize into micro- and nanometer-sized particles. The small particle size combined with the permanent structural charge of certain clays, notably those in the smectite class such as montmorillonite (MMT), saponite, and hectorite, results in significant surface reactivity which has profound implications in marine and terrestrial ecosystems, and provides the basis for a wide range of industrial, environmental, and agricultural applications. ${ }^{[20,21]}$ The long history of the use of clay minerals in the context of human health and disease is largely attributable to this rich electrochemistry.

In the case of smectites, the unit structure consists of layered sheets each constituted by two tetrahedral silica sheets sandwiching an octahedral sheet formed from a metal cation such as $\mathrm{Al}^{3+}$ or $\mathrm{Mg}^{2+}$ (Figure 2a). The smectite sheets are therefore isostructural with talc (ideally $\mathrm{Mg}_{3} \mathrm{Si}_{4} \mathrm{O}_{10}(\mathrm{OH})_{2}$ ) or pyrophyllite (ideally $\mathrm{Al}_{2} \mathrm{Si}_{4} \mathrm{O}_{10}(\mathrm{OH})_{2}$ ), but whereas the 2:1 sheets of talc are electrostatically neutral, the layers of the smectites possess a net negative charge (0.2-0.6 per half unit cell) due to random isomorphic cation substitutions in the octahedral and tetrahedral sheets compensated by hydrated interlayer cations. ${ }^{[20]}$ Compared with certain other 2:1 clay minerals such as illite and vermiculite, the net negative charge of smectites remain relatively weak allowing the interlayer spacing between associated unit layers to expand from 9.6 ̊ when dehydrated (or in the absence of alternative polar molecules) to complete delamination of individual layers (Figure 2b). ${ }^{[22]}$ As well as the structurally generated negative surface charge, broken bonds at the crystal edges with unsatisfied valences yield localized positive charges (or negative charges at high $\mathrm{pH}$ ) which play an important role in the colloidal properties of clay particle suspensions. The propensity for swelling and delamination of the charged smectite particles, gives rise to a rich selection of potential interactions between organic molecules and the clay particle surfaces, inter-layer pores and inter-particle spaces involving a range of mechanisms including cation exchange, hydrophobic interactions, hydrogen bonding, cation bridging, anion exchange and proton transfer depending on ambient $\mathrm{pH}$, and the size and electrostatic properties of the interacting molecule (Figure 3). ${ }^{[22]}$

Other relevant classes of clay mineral include kaolinite, palygorskite, and sepiolite. Kaolinite is a 1:1 tetrahedral octahedral phyllosilicate, the units of which stack to a greater degree than other clays. The layers of kaolinite are held together by hydrogen bonding supplemented with dipole-dipole and van der Waals interactions. The result is that kaolinite tends not to undergo interlayer expansion in water, though swelling can be induced in contact with certain compounds such as those able to form hydrogen bonds with the inter-layer surface

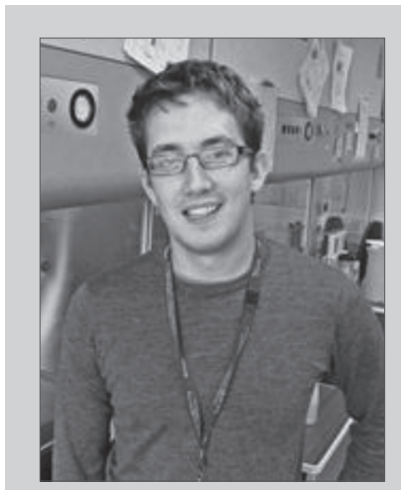

Jon Dawson is a research fellow in the Bone and Joint research group at the University of Southampton. $\mathrm{He}$ is part of the EU framework 7 'Biodesign' consortium developing regenerative treatments for degenerative and age related disorders of the bone, muscle, and heart. His PhD initiated research into clay-gels for cell and protein delivery. He has since worked on projects exploring stem-cell and material strategies for regeneration.

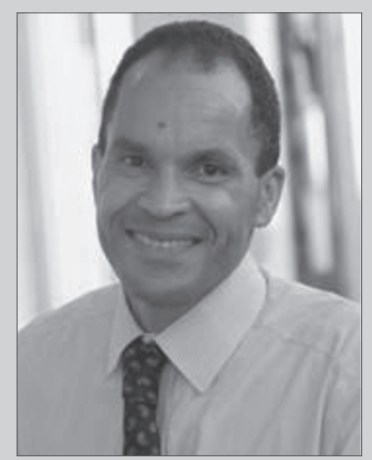

Richard Oreffo is Professor of Musculoskeletal Science and Associate Dean, Faculty of Medicine, University of Southampton. The Bone and Joint research group explores skeletal development and strategies for regeneration using stem cells (fetal, adult, embryonic and, more recently, induced pluripotent cell sources) and innovative scaffolds. His research is particularly focused on translational skeletal research for patient application and involves multidisciplinary research approaches involving tissue engineers, stem cell biologists, life scientists, and clinicians in developing approaches for bone and cartilage formation.

(e.g., hydrazine, amides, urea). ${ }^{[23]}$ The large degree of stacking significantly increases the electrochemical importance of the amphoteric edge surfaces, which exert a positive charge in acidic conditions and a negative charge above approximately pH 7. ${ }^{[22,23]}$ Palygorskite and sepiolite are hydrous magnesium silicates. Their 2:1 layered crystals form elongated ribbons rather than continuous sheets (as with smectites) formed by stepped linkages that result in a gross fibrous morphology incorporating channels along the fiber lengths. Substitution of aluminum by magnesium in the octahedral layers yield a moderately high permanent surface charge which, given the channeled fibrous structure, imparts a high sorptive capacity. In suspension palygorskite exhibits high viscosity that is derived from physical entanglement rather than electrostatic interaction (as with smectites) and which is, thus, stable in an ionic medium. ${ }^{[23,24]}$

The direct therapeutic relevance of the properties outlined can be briefly illustrated by returning to the list of pharmaceutical applications involving clays as active ingredients. Clays (principally palygorskite and smectites) are widely applied as antacids, with the postulated mechanism being the propensity to absorb protons to the mineral surface resulting in 


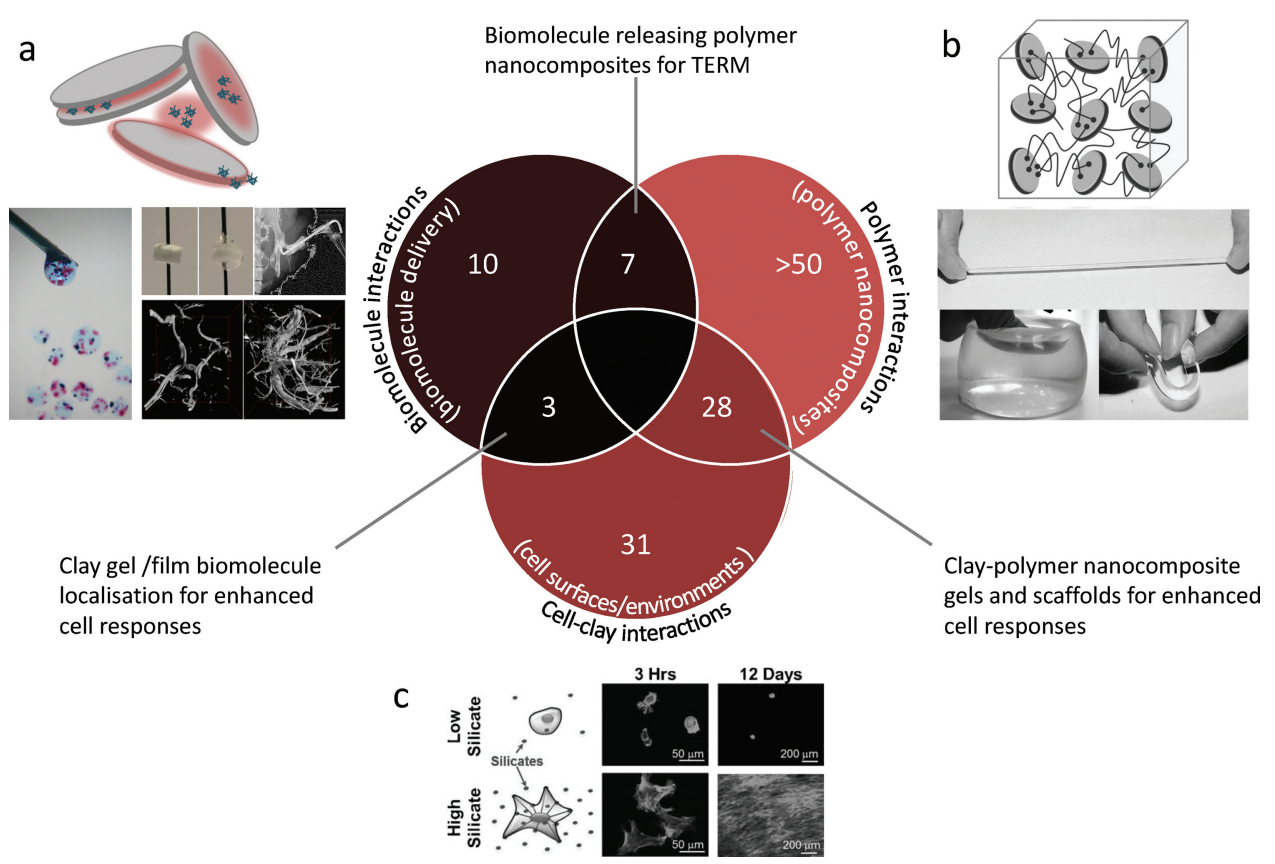

Figure 1. Clay interactions for TERM. Clay-biomolecule interactions, clay-polymer interactions, clay-cell interactions, and their combination are increasingly the subject of study in biomaterial design for application in TERM. a) Biomolecule interactions with clays allow the localization and delivery of proteins and growth factors. Adapted with permission. ${ }^{12]}$ Copyright 2011, Wiley-VCH. b) Polymer interactions with clays allow the generation of composites with enhances mechanical strength and toughness. Adapted with permission. ${ }^{[13,14]}$ Copyright 2002, 2006, American Chemical Society. c)

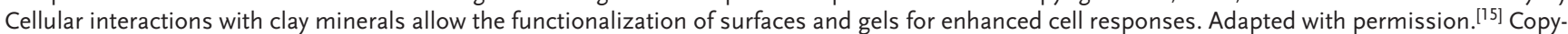
right 2012, Wiley-VCH. The Venn diagram displays the number of studies investigating these interactions that cite TERM as a potential application..

mineral decomposition into silica gel and structural or interlayer cations which are released as excretable products. ${ }^{[18]}$ As gastrointestinal protectors, the interaction of clay particles with mucosal glycoproteins mediates glycoprotein polymerization, thus stabilizing the protective mucosal barrier. ${ }^{[25]}$ Hence, smectites have been applied to successfully treat the symptoms of gastritis caused by non-steroidal anti-inflammatory drugs. ${ }^{[25}$ Smectite use in the treatment of symptomatic diarrhea derives from their ability to swell to absorb excess water and aid the compaction of feces. The high sorptive capacity of the silica gel that results in the acidic medium is thought to further aid anti-diarrheic action. ${ }^{[16-18]}$ As topical agents clay minerals (principally kaolinite, talc, and smectites) confer benefit by adhering to the skin, forming a protective film. Their sorptive capacity for grease and toxins is also frequently suggested in reviews of the subject. ${ }^{[16-18]}$

The sorptive properties of clay have also been widely investigated for their indirect therapeutic utility in the context of drug delivery and, recently, tissue regeneration. The recent development of polymer-clay nanocomposites have generated renewed interest in the properties of clay minerals and their utility to generate new functional materials, including biomaterials, with unique mechanical properties. Thus, alongside, classic clayprotein interactions, clay-polymer and, increasingly, clay-cell interactions are being investigated for their potential in various therapeutic strategies. It is these interactions and their combination for application in the design of biomaterials for tissue engineering and regenerative medicine that provides the focus of the rest of this report.

\section{Clay-Biomolecule Interactions}

\subsection{Proteins and Peptides}

While the interaction of clay minerals with biological molecules has been recognized for over a century ${ }^{[26]}$ it was in the 1960 s that its significance for medical applications began to be appreciated. Early studies observed reduced systemic availability of drugs co-administered with clay-based antacids and anti-diarrheal treatments, an observation which prompted investigation into the utility of clays as drug-delivery modifiers able to delay the release or localize the application of therapeutic molecules. ${ }^{[27]}$

The complex charge structure of proteins and potential for conformational entropy, combined with the rich electrochemistry of clay minerals facilitates a wide range of possible interactions and affinities that defy easy prediction. ${ }^{[28,29]}$ While electrostatic interactions are dominant, van der Waals and hydrophobic interactions are also significant and influenced by the internal cohesion of the protein secondary and tertiary structure. The several possible points of contact between clay and protein surfaces mean that high affinity (h-type) adsorption isotherms often pertain along with minimal desorption upon dilution. ${ }^{\text {[30] }}$

Recent studies have employed phage display techniques that allow the screening of extremely large libraries $\left(>1 \times 10^{9}\right)$ of 7-12 amino-acid length peptides, to identify sequences that bind to nanosized silica surfaces. ${ }^{[28,29,31,32]}$ There was considerable diversity observed in the sequences of the most tightly bound peptides both between studies and as a result of experimentally controlled changes to the silica conformations, suggesting the 


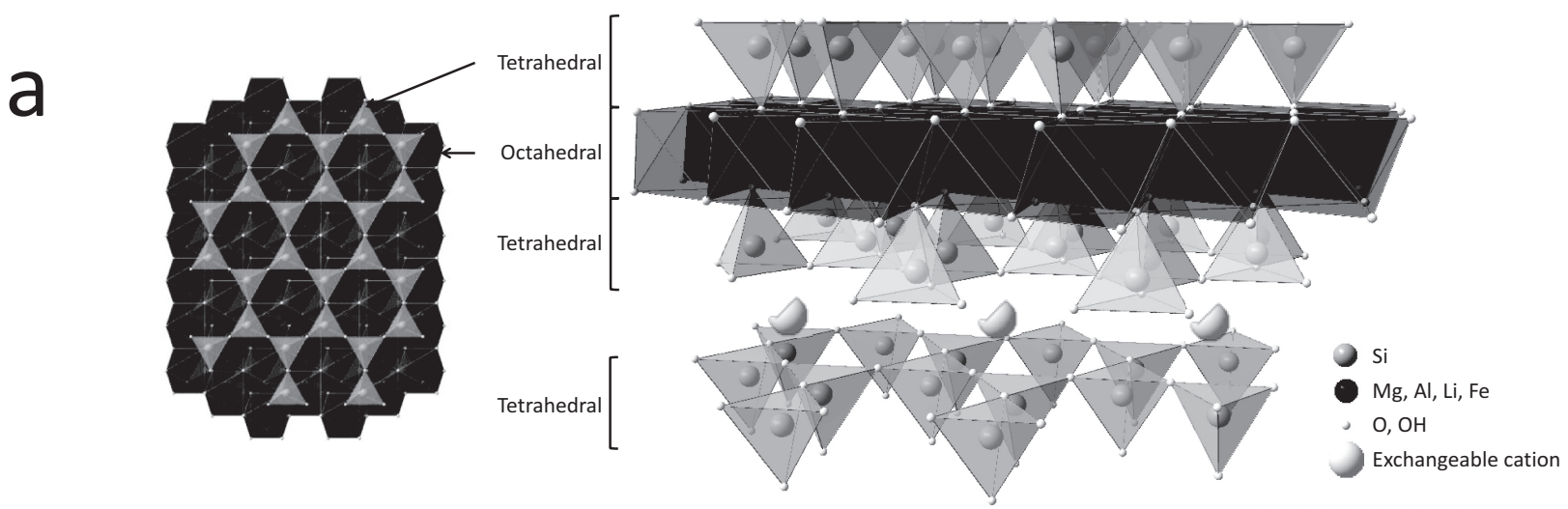

b

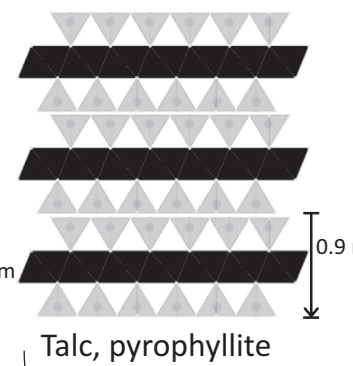

$1: 1$ type

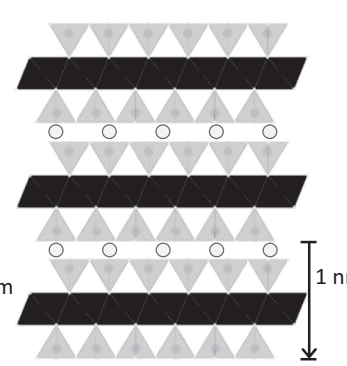

Illite, vermiculite

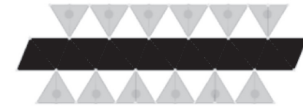

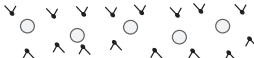

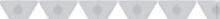
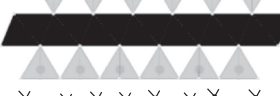

$v \forall v<v<v<v$

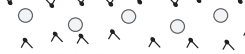
$\wedge \wedge \wedge \times 1.5 \mathrm{~nm}$

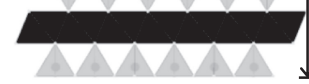

Smectites

Figure 2. a) Smectite crystals are constituted by two tetrahedral silica sheets sandwiching an octahedral sheet formed from a metal cation such as $\mathrm{Al}^{3+}$ or $\mathrm{Mg}^{2+}$. Charge deficiencies in the octahedral and/or tetrahedral layers yield a negative surface charge balanced by exchangeable cations. b) The different crystal structures of clays yield various colloidal properties and stacking arrangements. Compared with other clays, the relatively weak surface charge of smectites allows the complete delamination of individual layers.

high sensitivity of the silica-peptide interaction and, importantly, the existence of a range of binding mechanisms. ${ }^{[29]}$ For example, in a study of peptide binding to MMT, while the most strongly binding peptide contained positively charged Lysine side chains that at $\mathrm{pH} 7$ underwent an ion exchange reaction with the clay surface, another strong binder lacked any cationic groups and was bound via coordination of alkali ions and hydrogen bonds. ${ }^{[28]}$ Computer-simulations of the cation exchanged peptide suggested peptide conformational changes between the free and the adsorbed state, but that these changes were sequence specific and thus, not amenable to generalization. ${ }^{[31]}$ The identification of many peptide sequences showing affinity for silica surfaces stands in sharp contrast with equivalent studies on other surfaces such as gold, silver, and gallium arsenide, for which there was considerable convergence between high affinity sequences. ${ }^{[29]}$ This approach is now being explored as a means to functionalize clay surfaces via covalent attachment of high affinity peptides to target molecules. ${ }^{[28,32]}$

\subsection{Nucleic Acids}

As well as proteins and peptides, the adsorption of nucleic acids onto clay mineral systems has also been extensively studied in the context of soil ecology due to the capacity of smectite-adsorbed DNA in soil, to transform competent bacterial cells. ${ }^{[3-35]}$ In addition, smectites, particularly MMT, have long been proposed as catalytic surfaces for the putative polymerization of RNA oligomers in the "RNA World" hypothesis for the origin of biologic life. ${ }^{[36]}$ Model systems demonstrating this potential have since been developed. ${ }^{[37,38]}$

Studies within these fields have shown that DNA binding to MMT is not via intercalation as X-ray diffraction analysis indicates basal inter-gallery spacing remains the same following DNA absorption, but rather binding principally occurs on the edges of the clay particles. ${ }^{[39]}$ The extent of adsorption is greatest for chromosomal DNA compared with plasmid DNA and 25S RNA, ${ }^{[40]}$ and DNA adsorbed on MMT retains its original conformation. ${ }^{[34]}$ Importantly, several studies have demonstrated protection of clay-bound DNA from degradation by nucleases, ${ }^{[33,34,40,41]}$ which is thought to occur through their coadsorption onto the clay preventing DNA degradative interaction. ${ }^{[34]}$ The bioavailability of adsorbed nucleic acids have been assessed in the contexts of these two fields in terms of their transformative ability in competent bacteria ${ }^{[41]}$ and availability for reverse transcriptase replication. ${ }^{[36]}$ In both cases, efficiency was reduced but not eliminated with clay-bound compared to free nucleic acids. 


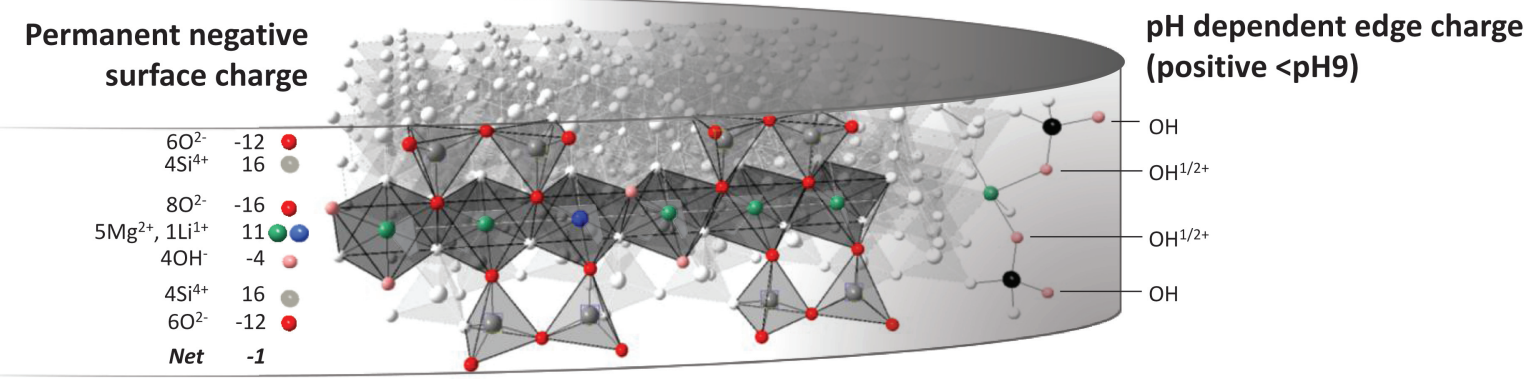

b

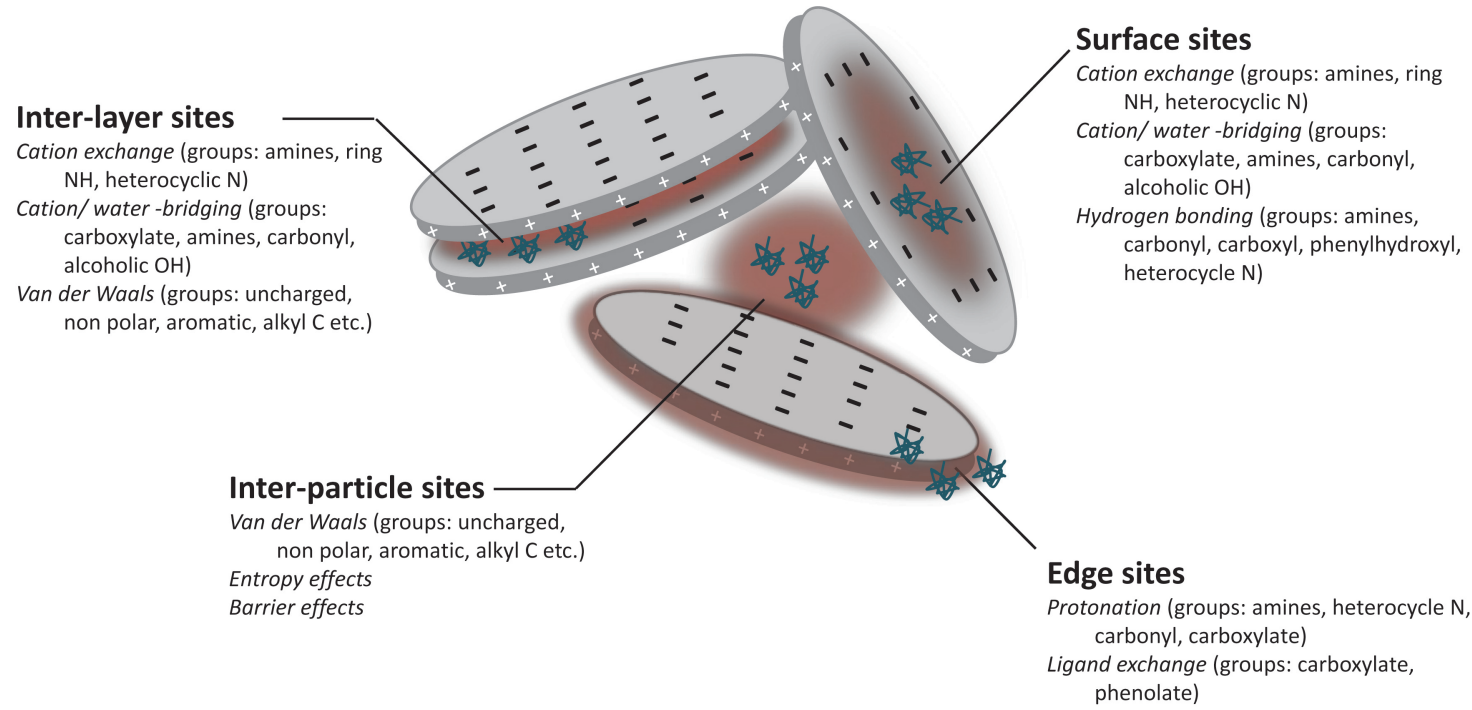

Figure 3. a) Smectites (here, the synthetic hectorite Laponite, $\left[\left(\mathrm{Si}_{8} \mathrm{Mg}_{5.5} \mathrm{Li}_{0.3}\right) \mathrm{O}_{20}(\mathrm{OH})_{4}\right]^{-0.7}$ ) possess a permanent negative surface charge arising from isomorphic substitutions in the crystal structure and a pH dependent edge charge from unsatisfied valences in the disrupted crystal lattice. b) Potential interactions between organic molecules and the clay particle surfaces, inter-layer pores and inter-particle spaces involving a range of mechanisms

\subsection{Therapeutic Delivery of Biomolecules}

The rich array of possible interactions between clay and biological molecules suggests exciting possibilities for biomolecule delivery. In the context of oral drug delivery, typical pharmacological formulations involve dispersing clay particles in drug solutions and, following equilibration, recovery of the drug-clay complex as a solid phase for delivery in tablet form. Thus, the intercalation of vitamin $\mathrm{B}_{6},{ }^{[42]}$ timolol maleate, ${ }^{[42]}$ itraconazole, ${ }^{[43]}$ donepezil, ${ }^{[44]}$ and venlafaxine ${ }^{[45]}$ into smectite particles has recently been investigated for controlled oral delivery. ${ }^{211,27,46,47]}$

The potential to employ clay nanoparticles for non-viral gene delivery is also being explored. The protective effect of clay particles has been convincingly demonstrated by the ability of clays to mediate the transfection of gastro-intestinal cells following oral delivery of DNA clay-complexes. In contrast to the delivery of naked DNA and DNA complexed with the widely used polyethyleneimine vector, detection of low levels of green fluorescent protein (GFP) transfection via polymerase chain reaction following delivery with MMT indicated protection against DNA degradation within both the acidic environment of the stomach and the nuclease-rich intestinal environment. ${ }^{[48]}$ The layered silicate rectorite was employed to enhance the utility of chitosan as a gene delivery vector. Incorporation of rectorite significantly improved the complexation of DNA compared with chitosan alone and enhanced the transfection efficiency to achieve $90 \%$ transfection after 5 days in vitro. Robust GFP expression in the gastrointestinal tract following oral delivery again indicated the protective effect of the clay on the plasmid. ${ }^{[49]}$ Another approach employed alkylammonium cations to expand the interlayer spacing of MMT for intercalation of DNA to achieve transfection of dermal fibroblasts, albeit at a low efficiency. ${ }^{[50]}$

\subsection{Clay-Modified Biomolecule Delivery from Matrices and Hydrogels}

Important to the function of the TERM matrix or scaffold is the ability to control, in space and time, the retention and release 

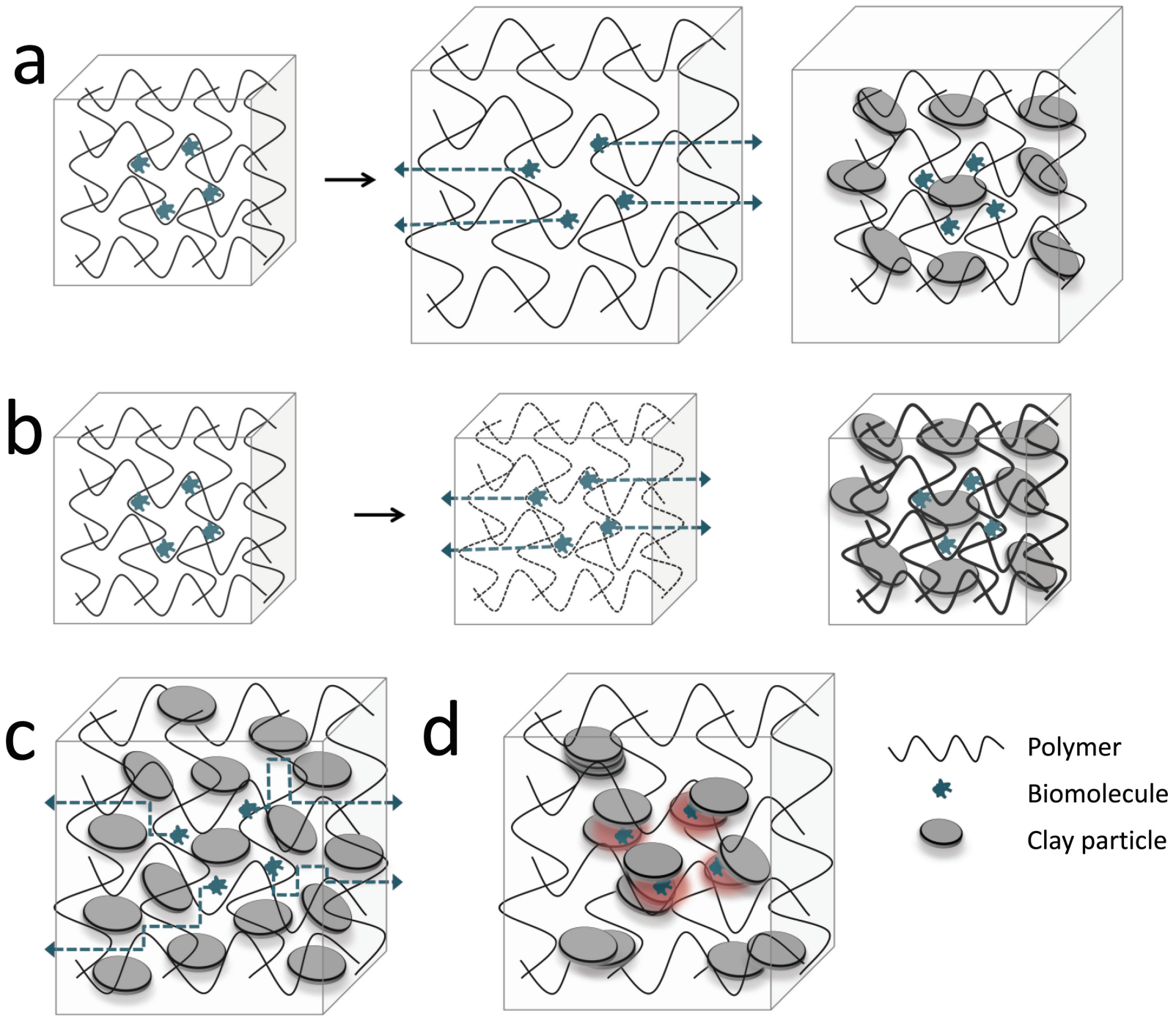

Figure 4. The incorporation of clay nanoparticles into polymeric matrices slows biomolecule release through a range of mechanisms including a) reduced swelling of the polymer, b) slowed degradation of the polymer, c) impartation of barrier properties, and d) direct interactions.

of bioactive molecules that stimulate and direct the growth and differentiation of tissue-progenitor populations. The characteristic open polymer networks and high water content $(>90 \%)$ of hydrogels in particular, while facilitating the diffusion of nutrients and contributing to the biocompatibility of the material, ${ }^{[51,52]}$ makes the sustained bioavailability of encapsulated molecules at the site of delivery a major challenge to be addressed prior to application. Typically, hydrogel encapsulation results in a burst-release response upon delivery, necessitating modifications to the polymeric network to retard the release of the biomolecule. ${ }^{[5,7,53]}$ With the generation of polymer-clay nanocomposite material science, the incorporation of clay nanoparticles into polymeric tissue-engineering matrices and hydrogels suggests exciting potential as one such modification for biomolecule localization and sustained release.

Interestingly, given the unique potential of clay particles for adsorption of biomolecules, their role in retarding drug release in the context of polymer-clay nanocomposites is relatively infrequently attributed to direct interaction between the biomolecule and the clay. ${ }^{[46,54]}$ This is possibly due to the fact that, to date, where nanocomposite materials have been applied to sustained delivery, clay-polymer interactions for altered mechano-physical properties (reviewed below) have dominated in the design process over clay-biomolecule interactions. ${ }^{[54]}$ For example, where retardation of protein (albumin) release was observed as a function of clay particle content in a dried poly(ethylene oxide) (PEO) hydrogel film, the slowing of release was attributable to a reduction in swelling of the polymer network due to increased clay cross-linkers rather than through direct association of the protein with the polymer-bound clay particles themselves. ${ }^{[55]}$ Clay-mediated swelling effects impacting drug release have been observed in several other studies (Figure 4a). ${ }^{[46,56-60]}$

The effect on matrix dissolution or degradation is another important indirect mechanism by which drug release is modified by clay incorporation (Figure 4b). Clay addition to a thermosensitive triblock copolymer system was observed to slow the release of a model protein via reduced hydrogel dissolution. ${ }^{[61]}$ Paracetemol diffusion from poly(ethylene glycol) (PEG) was likewise retarded by encasement with the modified MMT, 
Cloisite, which slowed the dissolution of the drug from the polymer. ${ }^{[62]}$ Conversely, addition of MMT nanoparticles to polyurethane increased the rate of the release of dexamethasone acetate, by increased water adsorption and thus, hydrolysis of the polymer. ${ }^{[63]}$

Slowed biomolecule release with incorporation of small fractions of exfoliated clay particles is most frequently accounted for by the impartation of barrier properties to polymer substrates that slow release via more tortuous diffusion paths (Figure 4c). ${ }^{[46,54,64-66]}$ For example, addition of Cloisite clay to poly(ethylene-co-vinyl acetate) slowed the rate of dexamethasone release from the polymer matrix, critically as a function of the aspect ratio (as well as the volume fraction) of the dispersed organosilicate particles. The authors suggest barrier properties could be harnessed by combining carefully selected silicates of different sizes to tune release profiles. ${ }^{[67]}$

However, in several studies, direct clay-biomolecule interactions have indeed been shown to impact biomolecule release (Figure $4 \mathrm{~d}$ ). Lee et al. ${ }^{[59,60,68]}$ investigated the effect of clay minerals on the swelling and drug release properties of two hydrogels. Incorporation of bentonite into a mucoadhesive polymeric hydrogel composed of acrylic acid (AA) and poly(ethylene glycol) methyl ether acrylate, ${ }^{[60]}$ and incorporation of MMT into a poly(N-isopropylacrylamide) (PNIPA) hydroge ${ }^{[59]}$ in both cases decreased the swelling and increased the strength of the hydrogel. Drug release was again altered indirectly as a function of reduced swelling, but also directly via electrostatic attraction of positively charged molecules (decreasing the rate of release) and electrostatic repulsion of the negatively charged molecules (increasing the rate of release). ${ }^{[59,60]}$ The introduction of an intercalation agent with MMT further reduced the swelling ratio but attenuated the previously described effect of the clay mineral on the drug release profile of the gel. ${ }^{[60]}$

The development of clay-chitosan polymer nanocomposites is particularly important in relation to biomolecule delivery in the context of tissue regeneration. Chitosan is a natural polymer derived from partially (75\%) deacetylated chitin with wide application as a polyelectrolye and chelating agent as well as use as a matrix material for regenerative applications. Intercalation of chitosan into smectites via amine induced cation exchange ${ }^{[69]}$ has been extensively investigated for a range of applications including drug delivery and, recently, tissue engineering. ${ }^{[57,69-78]}$ The intercalation of sodium modified MMT with chitosan was found to attenuate by competition the strong cationic exchange capacity of the clay increasing the release of an adsorbed cationic drug over time. ${ }^{[75]}$ Importantly, the clay mineral in this case was pre-loaded with the drug prior to formation of the chitosan-clay nanocomposite and thus the claydrug interaction was dominant in slowing release (represented schematically in Figure 4d). Subsequent incorporation of chitosan undermined this interaction in proportion to the ratio of chitosan to clay, providing a means to tune drug release. ${ }^{[75]}$ Interestingly, continued increase in the chitosan content relative to the cation exchange capacity of the clay has been found to generate the formation of bilayers of chitosan via hydrogen bonding between the amino and hydroxyl groups of the chitosan and clay substrate. As a result, exchange sites available for the adsorption of anionic drugs arise adding to the versatility of this system for biomolecule delivery. ${ }^{[69]}$
The utility of chitosan modified sodium MMT for sustained drug release has recently been applied in the development of a macroporous polycaprolactone (PCL) based scaffold for bone tissue engineering. ${ }^{[78]}$ Specifically, a PCL scaffold embedded with $\beta$-tri-calcium-phosphate and chitosan to enhance osteoconductivity, was loaded with chitosan-modified clay nanoparticles in order to sustain the release of the cationic broad-spectrum anti-tumor drug, doxorubicin. The rationale for biomolecule delivery in this case was the treatment of residual osteosarcoma following excision and prior to bone regeneration. Whereas in the absence of clay incorporation $95 \%$ of the drug was released within 4 days, release of the drug incorporated in association with chitosan modified clay particles was sustained for over two months. Critically, in the absence of chitosan modification, clay particle addition retarded release to less than $10 \%$ after 1 month. ${ }^{[78]}$

\subsection{Clay-Mediated Biomolecule Localization}

While classic drug-delivery strategies focus on the release properties of the delivery vehicle, regenerative strategies often require the presence and activity of the biomolecule to remain localized within or upon the tissue engineering matrix. This is especially the case for matrix molecules that facilitate cell adhesion and migration. The facility of clay in this regard has been underlined in the development of nanocomposite films through an approach known as layer-by-layer assembly. ${ }^{[79-82]}$ In one particular study, addition of a final (top) layer of clay particles upon sequentially layered poly(diallyldimethylammonium chloride) (PDDA)/MMT clay surface films, was found to be necessary for the sustained presence of the matrix molecules fibronectin and type IV collagen which, in turn, were found to enhance cell adhesion and growth upon the layered films. ${ }^{[80]}$ The observed impact of clay nanoparticle incorporation on improving cell adhesion in other nanocomposite approaches (reviewed below) has also been attributed, at least partly, to the role played by the clay particles in adsorbing adhesive proteins such as fibronectin and vitronectin from serum. ${ }^{[83-87]}$

Our group has explored the potential to localize active molecules through electrolyte-induced formation of gel capsules from pristine clay particles (Figure 5) with the aim of developing chemically defined niches for stem-cell mediated regeneration. Flocculation of clay particles in electrolyte solutions significantly enhances the sorptive capacity of clay and facilitates the entrapment of active molecules. ${ }^{[8]}$ Pre-dispersed nano-suspensions of the synthetic hectorite, Laponite displayed high and broad-spectrum affinity for proteins in saline solution (including cell culture media) following drop-wise addition and resultant gelation. Negligible release of either albumin (66.4 kDa, PI, 4.7) or lysozyme (14.4 kDa, PI, 11) from the clay gel capsules was observed and, furthermore, clay-gel capsule formation induced active uptake of the two proteins from the media via sorption to the gel capsule surface (Figure 6a). The utility of this approach to generate niches for tissue regeneration was demonstrated both with the matrix molecules fibronectin and type I collagen, and the angiogenic vascular endothelial growth factor (VEGF). Addition of fibronectin and type I collagen into clay gel films stabilized 

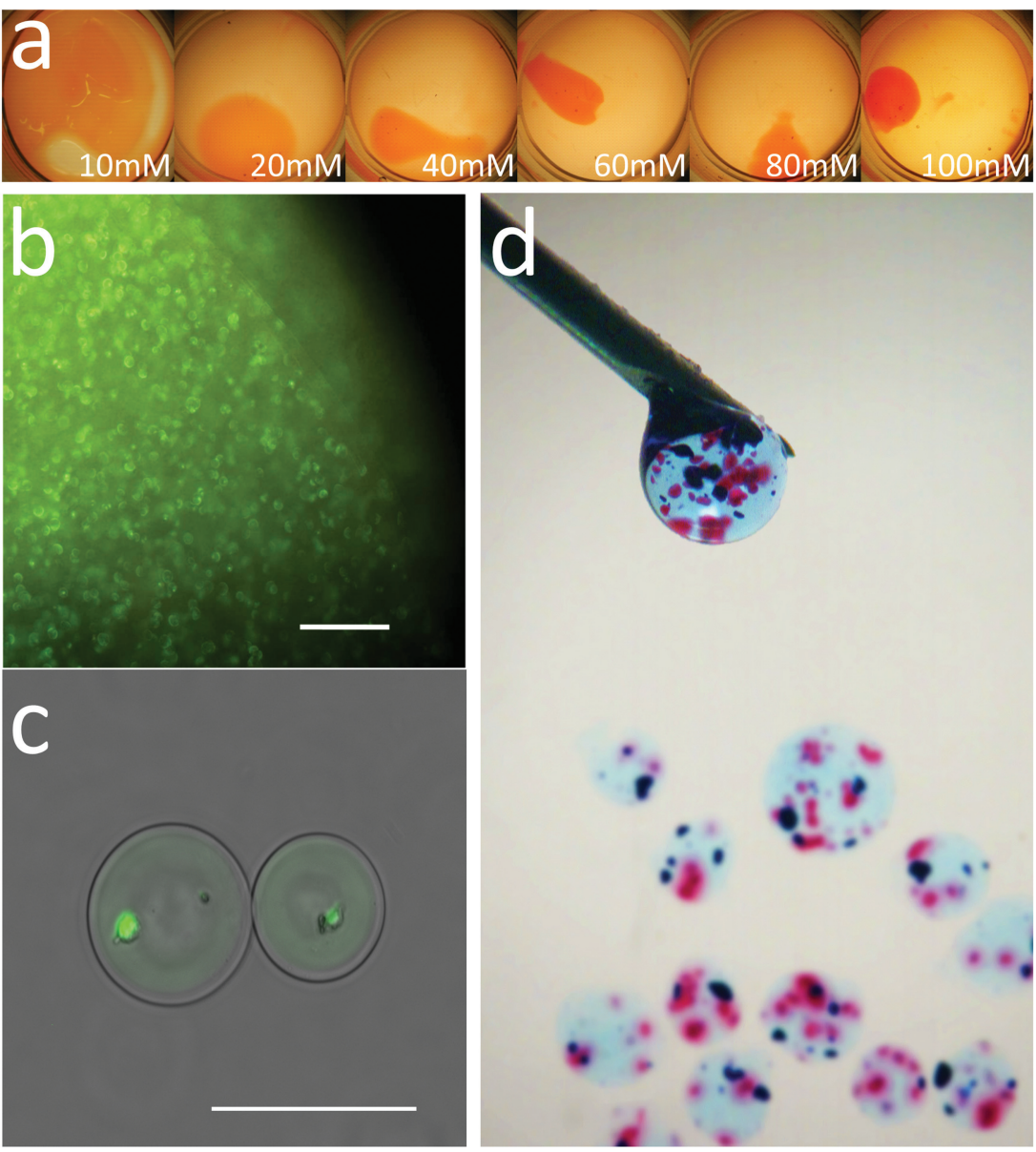

Figure 5. Clay gel encapsulation via controlled flocculation in response to electrolyte. a) Dropwise addition of hydrated Laponite suspensions to various concentrations $\mathrm{NaCl}^{-}$yields gel capsules as electrolyte concentration increases. b) Encapsulation of MG63 cells in Laponite via drop-wise addition to cell culture media. c) Atomized clay suspensions added to cell culture media allows single cell encapsulation. d) Recovery of microcapsules via centrifugation allows sub-encapsulation in clay gels to generate spatial complexity in an injectable system. Adapted with permission. ${ }^{[12]}$ Copyright 2011, Wiley-VCH. or smectites ${ }^{[93]}$ have also demonstrated strong clotting responses. Baker et al.[94] have investigated the mechanism of action of clay mineral induced hemostasis and the differential blood clotting response to a range of layered minerals which present varying structural and surface properties. The study observed a strong correlation between hemostatic efficiency and the strength of the zeta-potential of clay particles in simulated body fluid. The authors of the study suggested the correlation between clay surface charge and clotting efficiency to be due to the enhanced absorption and activation of blood coagulation factor XII on the more negatively charged clay surfaces in the presence of plasma proteins. ${ }^{[94]}$

These interesting results further underline the potential utility of clay-biomolecule interactions in tissue regeneration. The induction of a clotting response through potential localization of factors and cytokines is of direct relevance to regeneration at sites of trauma. The potential to sustain the presence and activity of inflammatory cytokines which stimulate the migration of progenitors would be of particular relevance in tissues with existing regenerative capacities such as bone where the formation of a clot and then callous are vital steps in the regenerative sequence. Of course, the same facility to retain inflammatory cytokines at an injury site is not purely beneficial, and so the ability to control and tune these interactions will likely be an important prerequisite for the safe and efficient utility of clay particles in regenerative interventions. the tubule formation of cultured endothelial cells (Figure 6b), co-encapsulation of fibronectin into clay gel capsules enhanced the chondrogenic differentiation of mesenchymal stem cells, and active uptake by clay gels of exogenously applied VEGF enhanced angiogenesis when the gels were implanted into a murine femoral defect (Figure 6c). ${ }^{[12]}$

\subsection{Clay-Protein Interactions and Clay Induced Hemostasis}

Finally, it is worth noting in the context of clay-protein interactions, the well-established facility of clay minerals to induce a hemostatic response. Kaolinite has been used since the 1950 s as a clotting agent in clinical assays of blood hemostasis and more recently clay minerals have been applied to wound dressing materials. QuickClot, a commercially available zeolite composite material has been shown to control bleeding in several animal models of lethal hemorrhage, ${ }^{[89,90]}$ and other dressings incorporating kaolinite ${ }^{[91,92]}$

\section{Clay-Polymer Interactions}

\subsection{Clay-Polymer Nanocomposites}

The challenging design specifications for functional biomaterials has driven the investigation and application of polymer nanocomposites that not only combine the respective benefits (and overcome the respective weaknesses) of organic and inorganic based materials but derive new emergent properties of critical relevance for TERM. ${ }^{[64]}$ Bone tissue sets the evolutionary precedent for this approach. ${ }^{[95,96]}$ The presence of a hydroxyapatite phase at the nanoscale of the hierarchically ordered (from molecular to macro-scale) collagen phase accounts for the high compressive strength of bone tissue, imparts to bone its vital role in mineral homeostasis and is of key significance for the differentiation and function of skeletal and hematopoietic cell populations. ${ }^{[97,98]}$ These features that characterize bone as a nanocomposite (a polymeric structure incorporating a nanoscale inorganic phase that enhances mechanical 

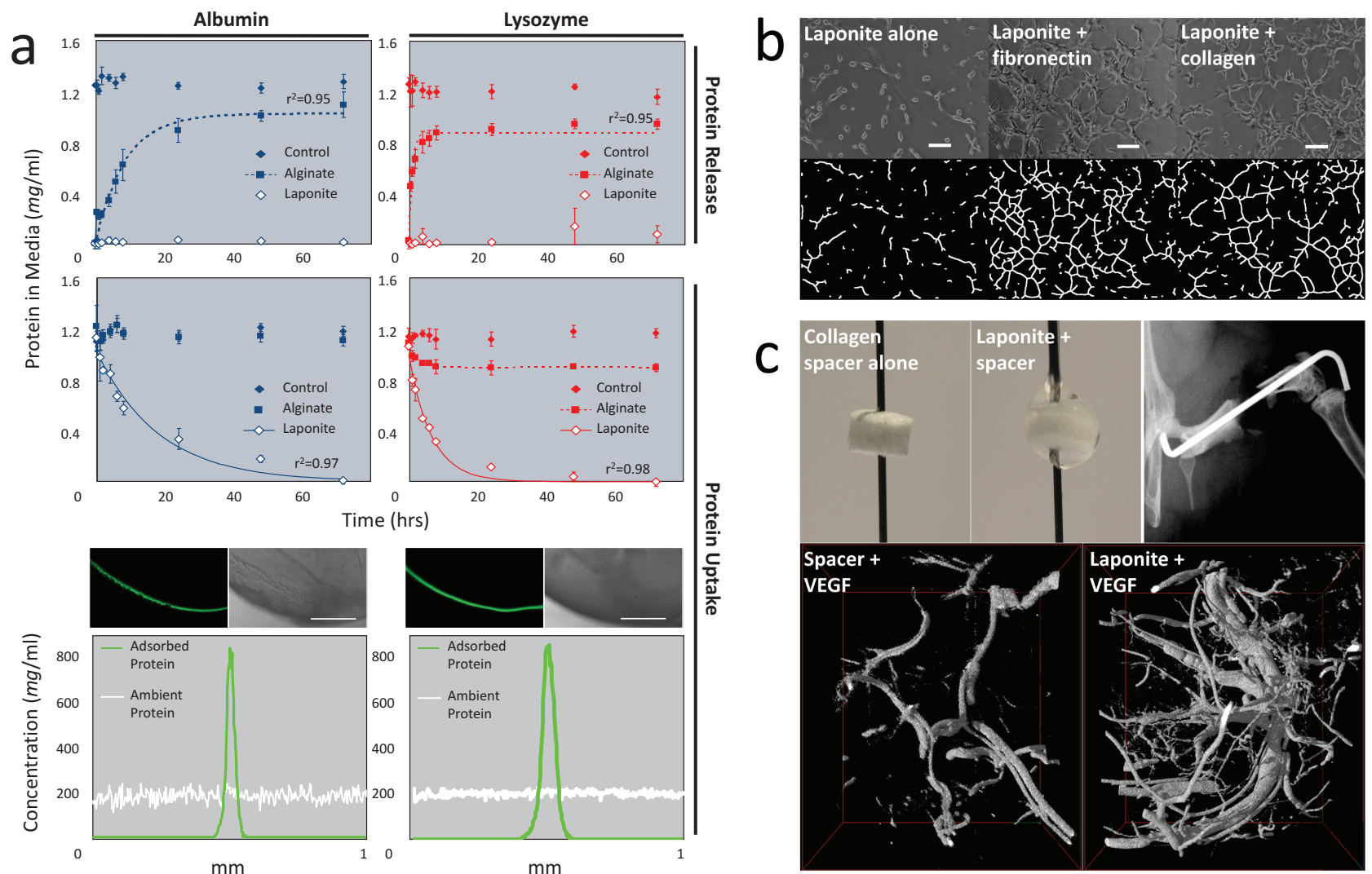

Figure 6. Biomolecule uptake and function in Laponite gels. a) Negligible release of model proteins was observed from Laponite gel capsules compared with alginate controls. Upon addition to saline solution containing protein, protein was taken up from the media and concentrated upon the surface of the gel capsule. Function of adsorbed protein was observed through premixing of the matrix molecules fibronectin and type I collagen into clay gel films to sustain b) network organization of endothelial cells in vitro (scale bars $100 \mu \mathrm{m}$ ) and c) through pre-incubation of Laponite gels in VEGF solutions to induce an in vivo angiogenic response in a murine femoral defect. Adapted with permission. ${ }^{[12]}$ Copyright $2011, \mathrm{Wiley}-\mathrm{VCH}$.

and chemical/biological properties) apply also to the development and goals of nanocomposites and their application in the context of TERM. ${ }^{[99]}$ Although initially developed for their potential to dramatically improve the mechanical properties of the polymer substrate, the biological significance of a clay nano-component for cell behavior is increasingly apparent as polymer-clay nanocomposites are investigated for biomaterial applications. In this section, the application of clay-polymer interactions for enhanced mechanical properties for regenerative strategies will be discussed before reviewing recent studies exploring the nature and significance of clay-incorporation for cellular interactions.

The potential of clay nanoparticle incorporation for the generation of polymeric materials with improved mechanical properties is attested to by the impressive volume of literature that has been generated on the subject in the last 10 years and their increasing application in almost all areas of modern industrial development and production. ${ }^{[100]}$ In the context of biomedical applications, inorganic clay mineral (along with silicon and calcium phosphate) nano-phases are increasingly being incorporated into polymers with established biocompatibility for the sake of enhancing the mechanical and degradation properties of the polymeric base. ${ }^{[64,101]}$ Typical improvements to the mechanical properties include enhanced tensile or compressive strength, enhanced modulus, elongation, toughness, and/or impartation of viscoelastic, or other responsive properties such as self-healing (Table 1).

\subsection{Clay-Polymer Nanocomposite Porous Scaffolds}

Clay nanoparticles have been applied to porous polymer scaffolds to enhance compressive strength and stiffness (modulus) ${ }^{[133-141]}$ The combination of high porosity and compressive strength remains an on-going challenge in scaffold design for tissue engineering, particularly in bone repair, and polymerclay nanocomposites have demonstrated considerable potential in this regard. Such enhancements derive not only from the combined mechanics of each component, as is predominantly the case with ceramic or nanotube-based composites, but critically from interfacial interactions between the polymer and clay nanoparticle. ${ }^{[142,143]}$ For this reason, significant improvements to the modulus and strength of a material can be achieved with the addition of clay concentrations of under $5 \mathrm{wt} \%$.

Given the importance of interfacial interactions, approaches that maximize their contribution to the composite structure by increasing the delamination and dispersion of individual clay particles are important in effecting improvements to 
Table 1. Polymer-clay nanocomposites investigated with stated relevance to biomedical applications together with observed mechanical enhancements.

\begin{tabular}{|c|c|c|c|c|c|c|c|c|c|c|}
\hline \multirow[t]{2}{*}{ Bulk class } & \multirow[t]{2}{*}{ Polymera) } & \multirow[t]{2}{*}{ Clayb) } & \multicolumn{7}{|c|}{ Mechanical enhancement with clayc) } & \multirow[t]{2}{*}{ Refs. } \\
\hline & & & $\begin{array}{c}\text { Tensile } \\
\text { strength } \\
{[\mathrm{MPa}]}\end{array}$ & $\begin{array}{c}\text { Tensile } \\
\text { modulus } \\
{[\mathrm{MPa}]}\end{array}$ & $\begin{array}{l}\text { Comp. } \\
\text { strength } \\
{[\mathrm{MPa}]}\end{array}$ & $\begin{array}{l}\text { Comp. } \\
\text { modulus } \\
{[\mathrm{MPa}]}\end{array}$ & Elongation & Toughness & $\begin{array}{l}\text { Dynamic } \\
\text { properties }^{d)}\end{array}$ & \\
\hline \multirow{13}{*}{$\begin{array}{l}\text { Dried film/ } \\
\text { gel }\end{array}$} & Chitin-PU & Bent- & 36 & & & & & & & [102] \\
\hline & Chitosan-gLA & MMT & & 260 & & & & & & [74] \\
\hline & Gelatin & MMT & 89 & 2000 & & & & & & [103] \\
\hline & PAA & Bent- & 0.4 & & & & + & & & [104] \\
\hline & PDMAA & Lap- & 15 & & & & + & + & & [105] \\
\hline & PEO & Lap- & 60 & & & & + & & MR & {$[15,106]$} \\
\hline & PGS & Hallo- & 1.6 & 1.5 & & & + & & & [107] \\
\hline & $\mathrm{PI}$ & MMT & 80 & 9000 & & & & & & [108] \\
\hline & PLG & MMT & 35 & 2140 & & & + & + & & [109] \\
\hline & PMEA & Lap- & 6.2 & 192 & & & + & + & & {$[105,110]$} \\
\hline & PU & MMT & 62 & 43 & & & + & + & MR & {$[111,116]$} \\
\hline & PVA & Hallo- & 60 & & & & + & + & & [117] \\
\hline & PVA & MMT & 320 & 5800 & & & & & & [118] \\
\hline \multirow[t]{5}{*}{ Fibrous } & BC & Lap- & 227 & 21000 & & & & & & [119] \\
\hline & BC & MMT & 210 & 6100 & & & & & & [120] \\
\hline & $\mathrm{PCL}$ & Hall- & 3.5 & 4.5 & & & & & & [87] \\
\hline & PEO & Lap- & 45 & & & & + & & MR & {$[106,121]$} \\
\hline & PLGA & Hallo- & 10 & 179 & & & + & & & [122] \\
\hline \multirow[t]{8}{*}{ Hydro-gel } & PAAM & Hallo- & 0.049 & 0.009 & 0.048 & & + & + & & [123] \\
\hline & PAAM & Lap- & 0.319 & 0.019 & & & + & + & & [124] \\
\hline & PDMAA & Lap- & 0.255 & 0.015 & & & + & + & $\mathrm{SH}, \mathrm{SR}$ & {$[105,125-126]$} \\
\hline & PEG & Lap- & 0.56 & & 3.73 & 0.038 & + & + & & {$[85,127-128]$} \\
\hline & PEO & Lap- & & & 0.012 & 0.003 & & & VE & {$[15,55]$} \\
\hline & Pluronic & Lap- & 0.077 & & & & + & + & & [129] \\
\hline & PNIPA & Lap- & 1.6 & 43 & 5 & & + & & $\mathrm{MR}$ & $\begin{array}{l}\text { [13-14], } \\
{[130-131]}\end{array}$ \\
\hline & PVA & MMT & & 3.8 & & & & & & [132] \\
\hline \multirow[t]{6}{*}{$\begin{array}{l}\text { Porous } \\
\text { scaffold }\end{array}$} & $\begin{array}{c}\text { Chitosan- } \\
\text { PGA }\end{array}$ & MMT & & & & 6.0 & & & & [133] \\
\hline & Gelatin & Sep- & & & 0.3 & 6.0 & & & & [134] \\
\hline & $\mathrm{PCL}$ & MMT & 11 & 420 & 3.6 & 43.1 & & & & [135-136] \\
\hline & PLA & MMT & & & 7.2 & 68.4 & & & & [137-138] \\
\hline & PLLA & MMT & & 170 & & & & & & [139-140] \\
\hline & PVA & Sep- & 0.4 & 15 & & & & & & [141] \\
\hline
\end{tabular}

a) BC, bacterial cellulose; gLA, g-lactic acid; PAA, polyester polyol acrylate; PAAM, polyacrylamide; PCL, poly(e-caprolactone); PDMAA, poly(N,N-dimethylacrylamide); PEC, poly(ethylene glycol); PEO, poly(ethylene oxide); PI, polyimide; PCA, polygalacturonic acid; PGS, poly(glycerol sebacate); Pluronic, Pluronic F127 diacrylate; PLA, poly(lactic acid); PLG, poly (lactide-co-glycolide); PLGA, poly(lactic-co-glycolic acid); PLLA, poly(l-lactic acid); PMEA, poly (2-methoxyethylacrylate); PNIPA, poly(N-isopropylacrylamide); PU, polyurethane; PVA, poly(vinyl alcohol); BC, bacterial cellulose; b) Bent, bentonite; Hallo, halloysite; Lap, Laponite; MMT, montmorillonite; Sep, sepiolite; ${ }^{c)}$ Maximum reported mechanical strength for each composite in MPa; ${ }^{d}$ Dynamic mechanical properties include self-healing (SH), stimuli-responsive (SR) visco-elastic (VE) and mechano-responsive (MR) properties.

mechanical properties. Organic modification of MMT through the use of organic ions, such as quaternary ammonium compounds, is commonly applied to increase the miscibility of the clay layers. In this way, the different degrees of miscibility in poly(l-lactic acid) (PLLA) that characterized modified MMTbased Cloisite clays, 15A, 25A, and 30B, were found to be significant in enhancing the modulus of the polymeric film prepared using an exfoliation-adsorption method (Figure 7). ${ }^{[140]}$ 

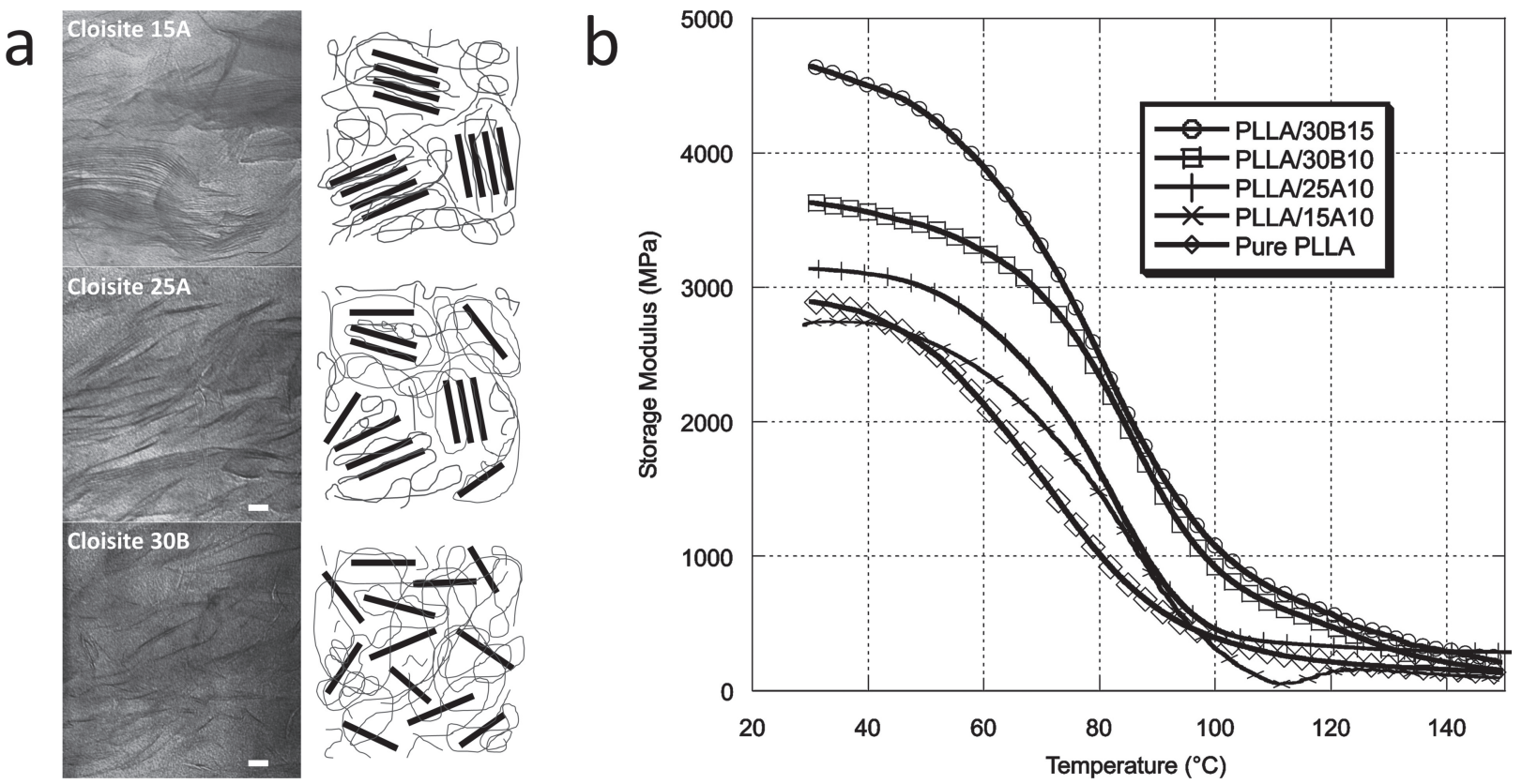

Figure 7. Increasing the delamination and dispersion of individual clay particles is important in effecting improvements to mechanical properties. a) Transmission electron microscopy images display various degrees of miscibility of modified MMTs in PLLA b) along with the corresponding improvement in mechanical properties. Adapted with permission. ${ }^{[140]}$ Copyright 2003, American Chemical Society.

Using the same approach, low concentrations (5.79\%) of organically modified MMT increased the tensile modulus of PLLA by $40 \%$ to allow the development of scaffolds of $90 \%$ porosity with a stiffness approaching that of intact trabecular bone. ${ }^{[139]}$ Additional approaches to enhancing the dispersion of clay particles further improve mechanics. Ozkoc et al. ${ }^{[138]}$ investigated the incorporation of Cloisite (30B) in porous poly(lactic acid) (PLA) scaffolds for bone tissue engineering and demonstrated the significance of shear rate for achieving higher degrees of exfoliation of the clay and a resultant increase in compressive modulus. Their approach achieved scaffolds of $80 \%$ porosity with a compressive strength of 2 $\mathrm{MPa}$, a result significantly higher than that typically reported for PLA matrices reinforced with calcium phosphates, silicates or phosphate glasses ${ }^{[144]}$ though still short of the 4-12 MPa of trabecular bone. ${ }^{[138]}$ The mechanical properties of PLA were further enhanced by Baker et al. ${ }^{[137]}$ who employed supercritical carbon dioxide (scCO2) processing to simultaneously aid the dispersion of the clay nanoparticles and impart a porous structure to a Cloisite (93A)-PLA nanocomposite. Using this approach, nanocomposites containing $2.5 \%$ clay mineral achieved an average compressive strength of $7.15 \pm$ 2.02 $\mathrm{MPa}$ and an average compressive modulus of $68.42 \pm$ $32.41 \mathrm{MPa} .{ }^{[137]}$ These approaches thus uniquely allow for the generation of hard porous scaffolds with strength and stiffness approximating that of trabecular bone offer considerable promise for bone tissue engineering applications.

\subsection{Clay-Polymer Nanocomposite Hydrogels}

Perhaps the most dramatic enhancements to mechanical properties have been seen in the application of clay nanoparticles to hydrogels. Haraguchi and colleagues, in particular, have explored the interaction of Laponite in polymer gels of $>90 \mathrm{wt} \%$ water to demonstrate the potential of this approach to generate new material properties. ${ }^{[13,14,84,105,110,125-127,130,145-147]}$ Nanocomposite hydrogels based, in the first instance, on PNIPA were found to display strength, modulus, and toughness several orders of magnitude greater than the polymer in the absence of clay. ${ }^{[13,130]}$ Such enhancements are attributable to the homogenous distribution of clay nanoparticles which act as non-covalent cross-linkages able to dissipate stress during deformation. ${ }^{[64]}$

Furthermore, the large size of the clay surfaces across which the polymer can form (and reform) multiple cross-linkages, generates physical hydrogels that combine unusually high mechanical strength with the capacity to self-heal allowing the potential for moldable and, in some cases, injectable biomaterials amenable for minimally invasive delivery. ${ }^{[15,64,105,126,148]}$

Several polymer-clay hydrogel systems have also been reported to display extremely large elastic deformations. ${ }^{[13,14,85,105,123-132]}$ In contrast to the often brittle organic polymers alone, nanocomposite gels, especially containing low $(<2 \%)$ concentrations of clay nanoparticles, characteristically display the capacity for elongation in excess of $1000 \%$ with near complete recovery. The large degree of spacing between the clay cross-linkers allowing long and flexible polymer chains, account for the considerable degree of deformation observed (Figure 8)..$^{[13,145,147]}$ Due to the extent of spacing, PNIPA nanocomposites incorporating higher clay contents (up to $12 \mathrm{wt} \%$ ) could be generated, displaying a marked increase in both tensile modulus and strength while maintaining the capacity for elongations of up to $1000 \%$. ${ }^{[14]}$ These gels also displayed mechano-responsive properties whereby, following elongations beyond a critical point and subsequent recovery, 
a

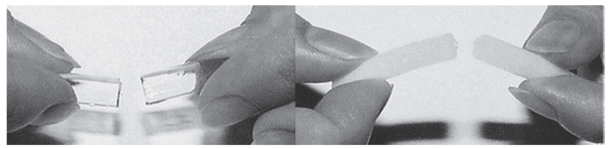

b

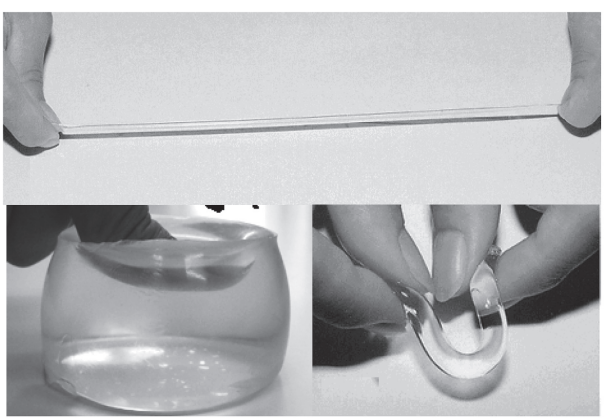

d
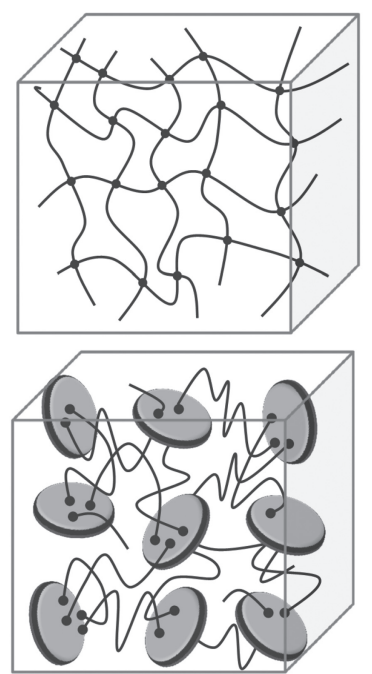

C
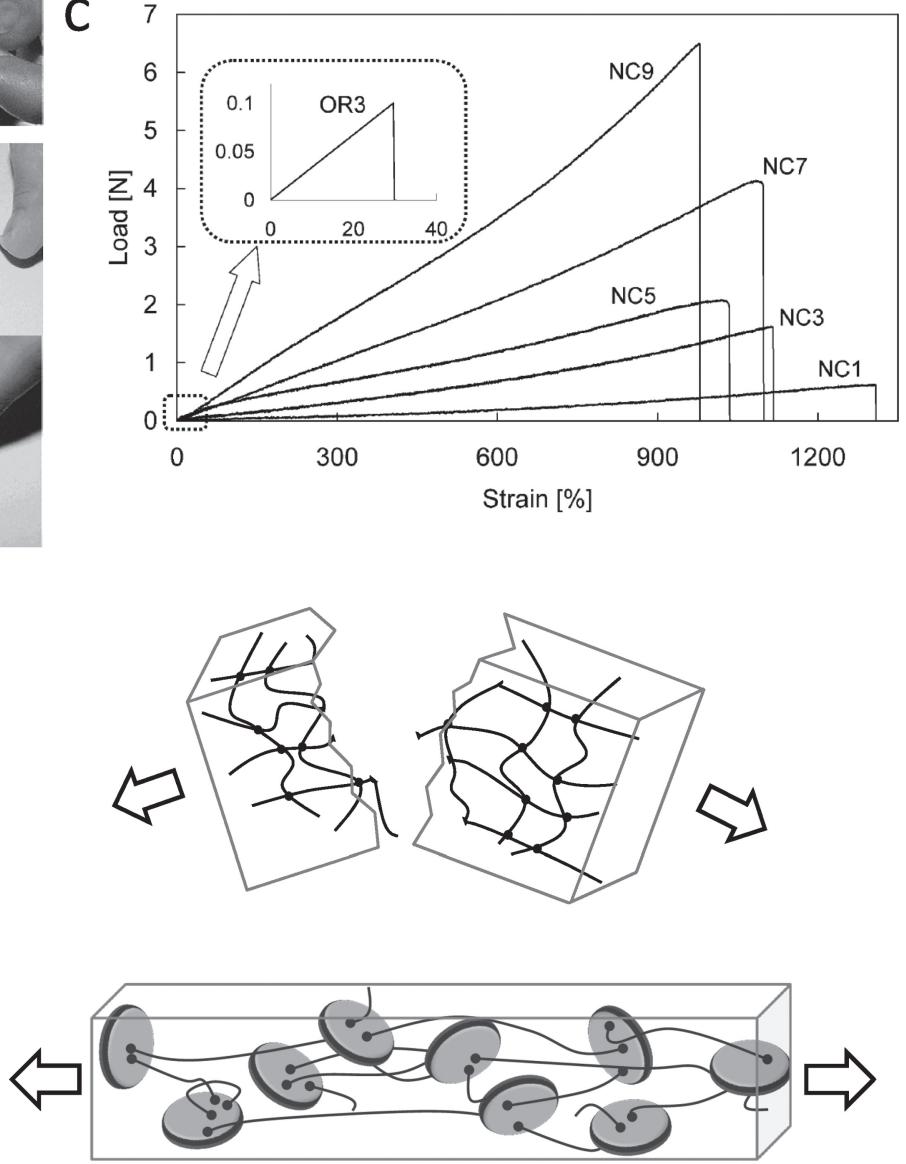

Figure 8. Nanocomposite hydrogels for enhanced mechanical properties. In contrast to a) organically cross-linked (OR) PNIPA polymer gels b,c) gels cross-linked with clay nanoparticles (NC) display marked improvements in strength, elongation and toughness (numbers represent relative crosslink density). d) The large degree of spacing between clay cross-linkers allow for long and flexible polymer chains. Adapted with permission. ${ }^{[13,14]}$ Copyright 2002, 2006, American Chemical Society.

a rigid gel with increased modulus, and strength was obtained due to a reorientation of the clay particles. ${ }^{[14,106,121]}$ This unique combination of injectability, providing the possibility of minimally invasive delivery of cells and biomolecules, with high mechanical strength and toughness, makes this approach of relevance for regeneration of a wide range of hard and soft tissues.

Despite these marked improvements in elastic modulus, the stiffness and toughness achieved are still, in these studies, an order of magnitude below that of soft-biological tissues. Recently however, Wang et al. $\left.{ }^{149}\right]$ have generated further improvements to the mechanics of PNIPA-Laponite nanocomposites by generating gels with an ordered layered structure mimicking that of nacre. This well ordered micro- and nanoscale structure allowed for the incorporation of Laponite particles constituting up to $30 \mathrm{wt} \%$ and achieved a dramatic, 360 -fold increase in elastic modulus (together with a five-fold increase in strength and a six-fold increase in toughness) compared with conventionally produced PNIPA-Laponite nanocomposite gels. The 1.5-43 MPa modulus of these ordered gels represents the highest reported value for a polymeric hydrogel to date, and, critically, achieves mechanical properties comparable to that of stiff biological tissues such as cartilage and cornea, further extending the possible applications of these materials for regenerative strategies. ${ }^{[149]}$

\section{Clay-Cell Interactions}

In response, largely, to the opportunities afforded by clay minerals for mechanical enhancement, an emerging cluster of studies have investigated the interaction of cells with materials incorporating clay nanoparticles. The application of clay nanoparticles and composites to regenerative medicine is still in its infancy however, and (with a few exceptions) little progress beyond relatively basic in vitro characterization of cellular responses to clay substrates has been reported. However, the data arising from these studies suggest intriguing potential for the control of cell function in the context of niche generation and tissue regeneration. 


\subsection{Biocompatibility}

Most studies describe no, or negligible, loss of cell viability or proliferation in the presence of clay minerals or materials incorporating clay minerals. Early studies on sepiolite-collagen complexes observed normal fibroblast proliferation and outgrowth of skin fibroblasts from explants ${ }^{[150,151]}$ and, while minimal bone ingrowth was observed upon implantation into an osseous cranial defect, there was no observed toxic or necrotic effect on local bone tissue. ${ }^{[152]}$ Laponite nanoparticles added directly to cell culture media did not impact on the viability of MC3T3-E1 pre-osteoblasts at doses up to $35 \mathrm{mg} \mathrm{mL}^{-1}$. ${ }^{[5]}$ Normal stromal cell morphology and proliferation was observed on Gelatin-MMT-chitosan scaffolds ${ }^{[70,71]}$ and no inhibition of fibroblast proliferation was observed on chitosan g-lactic acid MMT composites. ${ }^{[74]}$ Another study observed no stabilization of the foci of histone gamma H2AX, an indication of genotoxic action, in fibroblasts cultured on chitosan-MMT composite scaffolds. ${ }^{[153]}$ Polyurethane (PU)-MMT nanocomposites were also observed to be capable of sustaining the proliferation of cementoblasts. ${ }^{[111]}$ No acute oral toxicity has been observed in rats up to the maximum dose (5700 $\mathrm{mg} \mathrm{kg}^{-1}$ body weight) tested $^{[154-156]}$ and while MMT could be absorbed into the body within $2 \mathrm{~h}$, it was not observed to accumulate in the long term in any specific organ. ${ }^{[155,156]}$

A study of the toxicity of exfoliated MMT nanosilicate platelets showed no genotoxicity as assessed by three separate assays: the comet assay in Chinese hamster ovary (CHO) cells, an in vivo micronucleus assay in peripheral blood cells, and the Salmonella gene mutation assay. ${ }^{[154]}$ Another study confirmed negligible genotoxicity of sodium modified MMT (Cloisite $\mathrm{Na}^{+}$) in the Salmonella microsome and comet assays, but did observe a genotoxic response using filtered suspensions of Cloisite 30B. This was found to be attributable to the leached quaternary ammonium compounds which are frequently employed to enhance the dispersion of clay (particularly MMT) with polymer. $^{[157]}$ Quaternary ammonium compounds were also found to significantly inhibit cell growth when leached from the clay under simulated physiological conditions. In this study an alternative modifier, amino undecanoic acid was found to be of low toxicity and confer equivalent miscibility. ${ }^{[112]}$

Despite numerous studies that have observed normal, nontoxic cell or tissue responses, there remains a degree of ambiguity regarding the in vitro cytotoxicity of clay materials. Most studies have observed cytotoxicity only at high concentrations. For example, a loss of viability in $\mathrm{CHO}$ cells as indicated by the MTT assay and lactase dehydrogenase (LDH) release was observed at high doses of exfoliated MMT nano-silicate platelets $\left(\mathrm{IC}_{50}\right.$ of $\left.>1000 \mu \mathrm{g} \mathrm{mL} \mathrm{m}^{-1}\right) \cdot{ }^{[154]}$ Similarly, a study into clay minerals modified with an amine functional group observed minimal cytotoxicity through the MTT and LDH assays in four cell types at concentrations of $500 \mu \mathrm{g} \mathrm{mL}^{-1}$ and only moderate cytotoxicity at $1000 \mu \mathrm{g} \mathrm{mL}{ }^{-1}$. ${ }^{158]}$ Other studies have however described a more acute response. A significant loss of cell viability was observed in A549 lung epithelial cells following $24 \mathrm{~h}$ treatment with the nanoclays Bentone MA, ME-100, Cloisite $\mathrm{Na}^{+}$, Nanomer PGV, or Delilite LVF at concentrations of $25 \mu \mathrm{g} \mathrm{mL}{ }^{-1}$. $^{159]}$ Proliferation of INT-407 cells was inhibited at MMT concentrations above $100 \mu \mathrm{g} \mathrm{mL}-1$ after $24-72 \mathrm{~h}$ and clonogenicity was impeded at only $5 \mu \mathrm{g} \mathrm{mL}{ }^{-1}$ after 10 days. ${ }^{[156]}$ Another study observed a significant loss of viability of HEPG2 cells at only $1 \mu \mathrm{g} \mathrm{mL}^{-1}$ concentrations of Cloisite $\mathrm{Na}^{+}$after 24 h. ${ }^{[160]}$ It should be noted, however, that in these latter studies LDH leakage results did not correlate well with the loss of viability, being observed only at high clay concentrations, and thus telling against a direct effect of MMT on cell viability. ${ }^{[156,160]}$

More work is needed to elucidate the mechanisms for the potential in vitro cytotoxicity of certain clay formulations and to account for the lack of consistency between experiments assessing the biocompatibility of these materials. One important factor that remains to be sufficiently addressed in these studies is the importance of clay interactions with cell-culture media components which may mediate the impact of clay on in vitro cell viability. For example, a recent study has shown that increasing the concentration of the ubiquitous additive FCS from $2.5 \%$ to $5 \%$ attenuates the cytotoxic response of Human monocytic U937 cells to Cloisite $\mathrm{Na}^{+} .[161]$

Other questions remain about the long-term fate and biocompatibility of clay nanoparticles in vivo. These include the possibility and impact of their cellular uptake, their potential for dissolution within the inter- and intracellular spaces and the controversial importance of particle size and surface area in effecting the cytotoxicity of nanoparticles. ${ }^{[162]}$ Despite the longterm precedent of oral and topical administration of clay particles, clay minerals are not yet approved by regulatory agencies for implantation. Thus, considerable work is still required to confirm the long-term biocompatibility of the various clay minerals before clinical application for TERM strategies.

\subsection{Cell Adhesion and Proliferation}

Notwithstanding lingering questions regarding cytocompatibility, an increasing number of studies have shown not only normal cellular responses, but clay-dependent enhancements, particularly in respect to cell adhesion and proliferation upon polymeric matrices and gel substrates. Haraguchi et al. ${ }^{84]}$ investigated the effect of clay content in Laponite nanoparticle cross-linked PNIPA hydrogels on cell viability, adhesion, and proliferation. Consistent with previous studies ${ }^{[163,164]}$ organically cross-linked PNIPA polymeric hydrogels alone were unable to support the adhesion of proliferating cells. Clay crosslinked PNIPA however, was able to maintain both the adhesion and proliferation of HepG2, skin fibroblast, and human umbilical vein endothelial cells (HUVECs) in a manner strongly associated with the concentration of clay in the hydrogel. Interestingly above a critical concentration of clay $\left(7 \times 10^{-2} \mathrm{~mol} \mathrm{~L}^{-1}\right)$ cell adhesion was again impeded. The reason for the strong dependency of cellular adhesion on clay content in this system remains unclear but the authors propose attenuation of the hydrophobicity of the contracted PNIPA substrate by the hydrophilic clay particles, the surface anionic charges conferred by the clay and improved protein adsorption as possible explanations. Importantly, the previously established utility of PNIPA polymers grafted to tissue culture plastic (TCP) for temperature dependent cell sheet detachment ${ }^{[164]}$ is preserved in the clay-PNIPA nanocomposite hydrogels, allowing the use of this approach for cell-sheet engineering applications. ${ }^{[84,165]}$ 

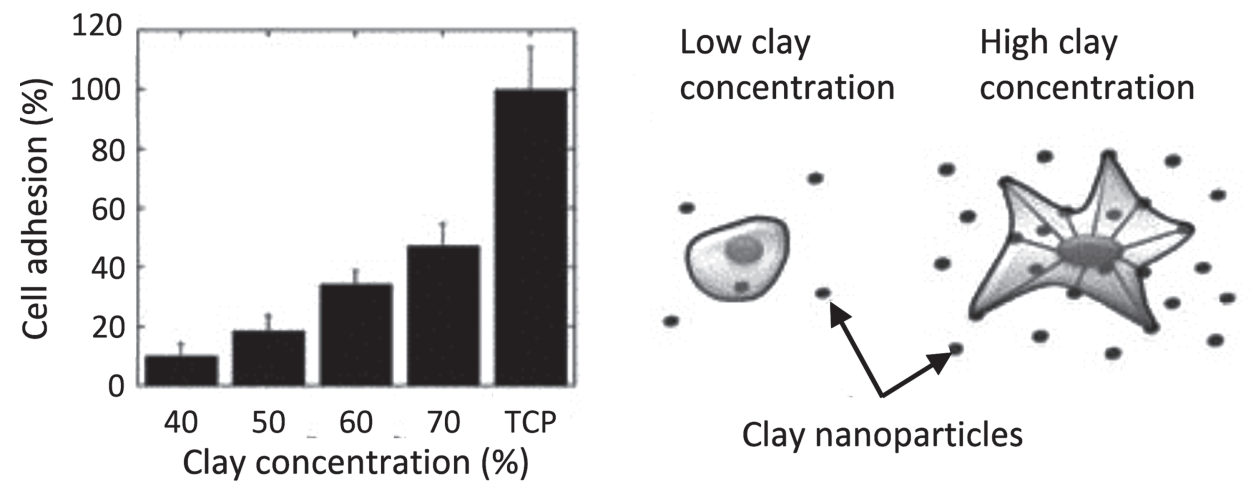

Clay nanoparticles
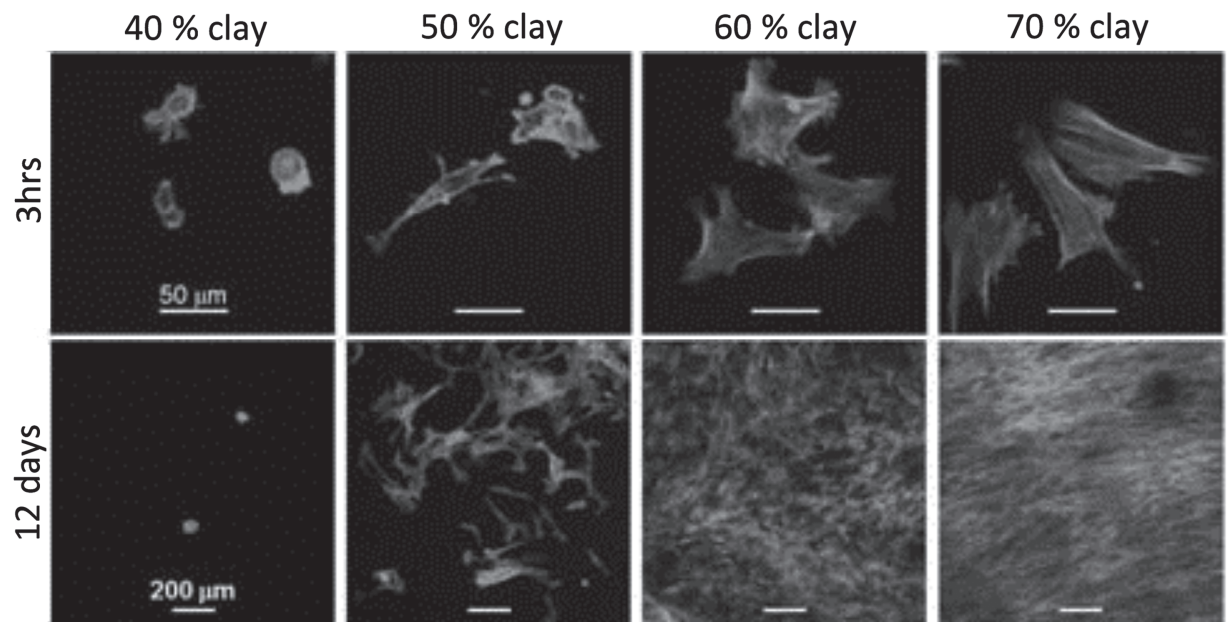

Figure 9. Improved adhesion and proliferation of MSCs on PEO gel films with increasing incorporation of Laponite nanoparticles. Adapted with permission. ${ }^{[15]}$ Copyright 2012, Wiley-VCH.

The same group also observed a bimodal response to clay content on MSC proliferation on 2-methoxyethyl acrylate (MEA) and N,N-dimethylacrylamide (DMAA) co-polymer clay nanocomposite gel films. In this case, while cell adhesion was dependent on the presence of clay nanoparticles and increasing the clay concentration from 0.02 molar to 0.05 molar further enhanced cell adhesion (recorded at day 3), the increase in clay concentration also coincided with a slowing of proliferation over the seven day culture period. ${ }^{[86]}$

Similar clay dependent effects on cell adhesion and proliferation have been seen in several other studies. Addition of $2.5 \mathrm{wt} \%$ Laponite was found to be sufficient to sustain the adhesion and proliferation of hMSCs on otherwise poorly cell adhesive PEG hydrogel films. The authors suggested a possible role for Laponite nanoparticles, both in providing adhesive sites for cell attachment and in facilitating protein adsorption. ${ }^{[85]}$ Enhanced adhesion of primary dermal fibroblasts onto chitosan films was improved with addition of $5 \% \mathrm{MMT}^{[153]}$ and enhanced proliferation of osteoblasts was also seen with MMT incorporation into chitosan-PGA films. ${ }^{[73]}$ In another study, the incorporation of $6 \mathrm{wt} \%$ MMT into a porous gelatin-cellulose composite reversed the observed negative impact of the cellulose component on cell viability and adhesion, and instead dramatically enhanced the proliferation of SAOS2 cells over and above the TCP control. The effect was further accentuated when the MMT content was increased to $12 \mathrm{wt} \%{ }^{[166]}$ Addition of 5\% Cloisite 20A clay significantly enhanced cell spreading and proliferation over ethylene vinyl acetate (EVA) films and addition of $10 \%$ clay further enhanced proliferation, which exceeded that observed on the glass surface control. Further increase in clay concentration however, impeded proliferation. The authors discuss the possible role surface modulus plays in this dynamic, though other possible factors including the concentration of leached organic modifier were not addressed. ${ }^{[112,167]}$

Recent work by Gaharwar and colleagues on Laponite-PEO nanocomposite films ${ }^{[15,55,77,83,106]}$ has started to shed some light on the function of clay in facilitating adhesion and proliferation of cells on polymeric gels. As with many of the polymers described above, PEO is hydrophilic and non-fouling and, thus, is resistant to cellular adhesion. The adhesion of NIH3T3 fibroblasts, ${ }^{[83,106]}$ MC3T3-E1 preosteoblasts, ${ }^{[55]}$ and mesenchymal stem cells ${ }^{[15]}$ was found to be highly dependent on the ratio of Laponite added to PEO such that only at ratios of Laponite to PEO of $40 \%$ and above were fibroblasts observed to adhere and proliferate (Figure 9). Increasing the clay content up to $70 \%$ further enhanced cell proliferation. Importantly, this effect was consistently observed not only in the growth phase, but also in the total number of cells reached at the (sub-confluent) plateau phase, indicating the availability of adhesion sites provided by the clay to be a controlling factor. ${ }^{[83,106]}$ Furthermore, fibroblast 
adhesion was indeed found to be highly dependent on the presence of serum proteins in the media, as suggested by several of the above studies. Interestingly, in contrast to tissue culture polystyrene and PEO diacrylate controls, some cell adhesion following a clay concentration trend was still observed in serumfree conditions. Thus, in addition to providing protein adhesion sites, these studies suggest direct cell-clay interactions can also mediate cell adhesion, albeit less efficiently, in the absence of adhesive factors adsorbed from the serum. ${ }^{[83]}$

\subsection{Cell Differentiation}

The possibility of harnessing clay minerals for the induction of cellular differentiation is implied by the well-established utility of clay minerals for the localization of biomolecules. To date however, this possibility has been scarcely explored for regenerative strategies. In preliminary studies, we have demonstrated the potential to enhance the chondrogenic differentiation of MSCs in electrolyte induced clay colloid gel capsules by co-localizing the matrix molecule fibronectin with the encapsulated populations. ${ }^{[12]}$

Aside from the largely unexplored potential of clay nanoparticles to mediate the differentiation of regenerative populations via the localization of biological signals, several studies have suggested the utility of clays to stimulate the osteogenic induction of responsive cells via direct clay-interactions. For example, the response of a pre-osteoblast cell line to osteogenic induction has been investigated as a function of Laponite content in PEO nanocomposite film surfaces. ${ }^{[55]}$ Similar to the observed Laponite-dependent enhancement of adhesion and proliferation of preosteoblasts described above, an increase in Laponite concentration from $40 \%$ to $70 \%$ resulted in a 10 -fold increase in alkaline phosphatase activity and a 12 -fold increase in mineralized matrix production after 28 days in vitro culture. The authors discuss the potential effect of Laponite nanoparticles in directly upregulating osteogenesis via the elution of Mg2+ and silicate ions, a function well-established in bioglass, another silicate based material, and certain bioactive ceramics. ${ }^{[55]}$ It should be noted however, that in this case, the enhanced response to induction could be accounted for simply as a function of improved cell adhesion and spreading conferred by Laponite, particularly since the alkaline phosphatase expression did not exceed that observed in the TCP control. Another study by the same group investigating osteogenic induction of human MSCs (passage 5) on PEO-Laponite nanocomposites, did however observe enhanced upregulation of osteocalcin mRNA compared to controls raising the possibility of direct clay induced enhancement of osteogenesis. ${ }^{[15]}$

Further evidence suggesting a role for clay nanoparticles as a source of osteoinductive silica species was also presented in a study in which silk fibroin films were doped with Cloisite $\mathrm{Na}^{+}$. Compared with TCP and sodium silicate modified silk films, human MSCs (passage 2/3) cultured on MMT treated films for 14 days in osteogenic culture conditions showed significantly increased expression of alkaline phosphatase, bone sialoprotein, and type I collagen compared to controls. The authors inferred that the presence of low levels of silica ions detected by inductively coupled plasma analysis in MMT treated samples may account for the enhanced osteogenic response. ${ }^{[168]}$ Another study observed enhanced MSC osteogenesis on electrospun PCL nanocomposite fibers that incorporated halloysite as matrices for bone tissue engineering. Interestingly, this study observed that the addition of $4 \%$ halloysite improved both protein adsorption and the deposition of hydroxyapatite (HA) from simulated body fluid compared with PCL fibers alone. ${ }^{[87}$ The ability of the inter-gallery regions of organically modified MMT to act as sites for the mineralization of HA was also observed in a further study. The generated HA-organoclay nanoparticles were subsequently incorporated into Chitosan PGA films to support the adhesion and growth of human osteoblasts. ${ }^{[169]}$ These pioneering studies into the utility of clay minerals to induce the osteogenic differentiation of osteoprogenitors thus suggest a range of possible mechanisms. As well as acting as a potential source of osteoinductive ions the ability of clay minerals to enhance cellular adhesion, adsorb protein and facilitate mineralization may also play a role in the observed enhancement of osteogenesis. Further studies are thus warranted to elucidate and confirm this novel application for clay minerals.

\section{Conclusions and Future Directions}

This Progress Report has described the interactions of clay nanoparticles with biological molecules, polymers, and cells. Each of these interactions present new opportunities for TERM that are only beginning to be explored (Figure 1). We have described the application of clay-biomolecule interactions in drug and gene delivery systems, including drugrelease from polymeric matrices and scaffolds. As well as controlled release, the utility of clay nanoparticle systems to localize biological signaling has recently been explored in the development of spatially complex regenerative microenvironments. ${ }^{[12,80]}$ While the rich array of potential binding mechanisms/sites clay minerals offer provides considerable potential for this, it also presents challenges in predicting the precise nature of protein-clay interactions and the resulting bioavailability and efficacy of the localized molecule. Such complexity suggests the need for high-throughput empirical approaches able to confirm the biological function of molecules in association with clay nanoparticles. A further avenue still to be explored in the context of TERM is the utility of clay nanoparticles for gene delivery in situ. The ability to both sustain and localize the influence of a delivered vector is an ongoing challenge and the established ability of clay minerals to bind nucleotides, and offer a degree of protection from enzymatic digestion could contribute in the pursuit of a safe and reliable in situ transfection technology.

Of the interactions reviewed, clay-polymer interactions remain the most extensively investigated. This Progress Report has described the unique ability of clay-polymer nanocomposites to marry important biomaterial parameters such as porosity or self-organization with mechanical strength and toughness. The ability to generate strong porous scaffolds with strength and stiffness equivalent to trabecular bone, and polymeric hydrogels combining the potential for minimally invasive delivery with the toughness characteristic of soft biological tissues, extends the potential utility of these materials across 
almost the entire range of hard and soft tissue regeneration applications.

The success of this approach and the potential it offers for biomaterial design has, to date, been the main drive behind investigations into clay-cell interactions (Figure 1). The enhancements in cell adhesion, proliferation, and differentiation in response to clay nanoparticles observed in these studies suggest intriguing potential for control of cellular responses to biomaterial surfaces and warrant further work elucidating the mechanisms involved.

The application of these material strategies presents considerable potential for the generation of multifunctional scaffolds for TERM strategies. While, as noted in the introduction, the inductive role of the TERM scaffold is increasingly emphasized within the field, the marrying of such regenerative functions with the still vital "conductive" clinical design constraints such as mechanical support and minimally invasive delivery remains a considerable challenge in scaffold design. ${ }^{[1]}$ If the interactions described in this Progress Report can be successfully harnessed in combination to allow concurrent localization of biological molecules, enhancement of polymer mechanics, and induction of cellular responses, this significant challenge to the clinical translation of regenerative strategies may begin to be met.

\section{Acknowledgements}

The authors would like to thank the members of the Bone and Joint research group for useful discussions. J.I.D. and R.O.C.O. are grateful recipients of funding from Wessex Medical Research, Rosetrees Trust, BBSRC (LOLA BB/G010579) and EU Framework 7 (BIODESIGN).

Received: March 7, 2013

Revised: April 4, 2013

Published online: May 31, 2013

[1] M. Bongio, J. J. J. P. van den Beucken, S. C. G. Leeuwenburgh, J. A. Jansen, J. Mater. Chem. 2010, 20, 8747.

[2] T. Dvir, B. P. Timko, D. S. Kohane, R. Langer, Nat. Nanotechnol. 2010, 6, 13

[3] M. Lutolf, J. Hubbell, Nat. Biotechnol. 2005, 23, 47.

[4] J. Patterson, M. M. Martino, J. A. Hubbell, Mater. Today 2010, 13, 14.

[5] M. M. Stevens, A. Khademhosseini, Soft Matter 2010, 6, 4962.

[6] D. Williams, J. Miner. Metals Mater. Soc. 2011, 63, 51.

[7] K. Lee, E. A. Silva, D. J. Mooney, J. R. Soc. Interfaces 2011, 8, 153.

[8] D. Dado, S. Levenberg, Semin. Cell Dev. Biol. 2009, 20, 656.

[9] E. Kingham, M. Tsimbouri, N. Gadegaard, M. Dalby, R. Oreffo, Bone 2011, 48, S108.

[10] K. Kulangara, K. W. Leong, Soft Matter 2009, 5, 4072.

[11] J. I. Dawson, R. O. C. Oreffo, Arch. Biochem. Biophys. 2008, 473, 124.

[12] J. I. Dawson, J. M. Kanczler, X. B. Yang, G. S. Attard, R. O. C. Oreffo, Adv. Mater. 2011, 23, 3304.

[13] K. Haraguchi, T. Takehisa, S. Fan, Macromolecules 2002, 35, 10162.

[14] K. Haraguchi, H. J. Li, Macromolecules 2006, 39, 1898.

[15] A. K. Gaharwar, V. Kishore, C. Rivera, W. Bullock, C.-J. Wu, O. Akkus, G. Schmidt, Macromol. Biosci. 2012, 12, 779 .

[16] M. I. Carretero, C. S. F. Gomes, F. Tateo, in Handbook of Clay Science, Vol. 1 (Eds: F. Bergaya, B. K. G. Theng, G. Lagaly), Elsevier, Amsterdam, Netherlands 2006, 717
[17] M. I. Carretero, Appl. Clay Sci. 2002, 21, 155.

[18] M. I. Carretero, M. Pozo, Appl. Clay Sci. 2010, 47, 171.

[19] M. I. Carretero, M. Pozo, Appl. Clay Sci. 2009, 46, 73.

[20] G. Sposito, N. T. Skipper, R. Sutton, S. Park, A. K. Soper, J. A. Greathouse, Proc. Natl. Acad. Sci. USA 1999, 96, 3358.

[21] E. Ruiz-Hitzky, P. Aranda, M. Darder, G. Rytwo, J. Mater. Chem. 2010, 20, 9306

[22] G. Lagaly, in Developments in Clay Science, Volume 1 (Eds: B. K. G. T. Faïza Bergaya, L. Gerhard), Elsevier, Amsterdam, Netherlands 2006, 141

[23] B. K. G. Theng, in Developments in Clay Science, Volume 4 (Ed: B. K. G. Theng), Elsevier, Amsterdam, Netherlands 2012, 3.

[24] H. H. Murray, Appl. Clay. Sci. 2000, 17, 207.

[25] M. T. Droy-Lefaix, F. Tateo, in Developments in Clay Science, Vol. 1 (Eds: B. K. G. T. Faïza Bergaya, L. Gerhard), Elsevier, Amsterdam, Netherlands 2006, 743.

[26] T. Schloesing, Comp. Rend. Acad. Sci. Paris 1874, 78, 1276.

[27] C. Aguzzi, P. Cerezo, C. Viseras, C. Caramella, Appl. Clay. Sci. 2007, 36, 22.

[28] H. Heinz, Clay Miner. 2012, 47, 205

[29] S. V. Patwardhan, F. S. Emami, R. J. Berry, S. E. Jones, R. R. Naik, O. Deschaume, H. Heinz, C. C. Perry, J. Am. Chem. Soc. 2012, 134, 6244.

[30] B. K. G. Theng, in Developments in Clay Science, Vol. 4 (Ed: B. K. G. Theng), Elsevier, Amsterdam, Netherlands 2012, 245

[31] H. Heinz, J. Comput. Chem. 2010, 31, 1564.

[32] L. F. Drummy, S. E. Jones, R. B. Pandey, B. L. Farmer, R. A. Vaia, R. R. Naik, ACS Appl. Mater. Interfaces 2010, 2, 1492.

[33] M. Khanna, G. Stotzky, Appl. Environ. Microbiol. 1992, 58, 1930.

[34] P. Cai, Q. Y. Huang, X. W. Zhang, Environ. Sci. Technol. 2006, 40, 2971.

[35] G. Pietramellara, M. Franchi, E. Gallori, P. Nannipieri, Biol. Fertility Soils 2001, 33, 402

[36] M. Franchi, E. Gallori, Gene 2005, 346, 205

[37] J. P. Ferris, A. R. Hill, R. Liu, L. E. Orgel, Nature 1996, 381.

[38] W. Huang, J. P. Ferris, Chem. Commun. 2003, 1458.

[39] M. Khanna, M. Yoder, L. Calamai, G. Stotzky, Sci. Soils 1998, 3, 1.

[40] M. Franchi, E. Bramanti, L. Morassi Bonzi, P. Luigi Orioli, C. Vettori, E. Gallori, Origins Life Evol. B. 1999, 29, 297.

[41] S. Demanèche, L. Jocteur-Monrozier, H. Quiquampoix, P. Simonet, Appl. Environ. Microbiol. 2001, 67, 293.

[42] G. V. Joshi, B. D. Kevadiya, H. A. Patel, H. C. Bajaj, R. V. Jasra, Int. J. Pharm. 2009, 374, 53.

[43] H. Jung, H.-M. Kim, Y. B. Choy, S.-J. Hwang, J.-H. Choy, Int. J. Pharm. 2008, 349, 283

[44] J. K. Park, Y. B. Choy, J. M. Oh, J. Y. Kim, S. J. Hwang, J. H. Choy, Int. J. Pharm. 2008, 359, 198.

[45] H. A. Patel, S. Shah, D. O. Shah, P. A. Joshi, Appl. Clay Sci. 2011, $51,126$.

[46] C. Viseras, C. Aguzzi, P. Cerezo, M. C. Bedmar, Mater. Sci. Technol. 2008, 24, 1020

[47] C. Viseras, P. Cerezo, R. Sanchez, I. Salcedo, C. Aguzzi, Appl. Clay Sci. 2010, 48, 291.

[48] M. Kawase, Y. Hayashi, F. Kinoshita, E. Yamato, J. Miyazaki, J. Yamakawa, T. Ishida, M. Tamura, K. Yagi, Biol. Pharm. Bull. 2004, 27, 2049.

[49] X. Wang, X. Pei, Y. Du, Y. Li, Nanotechnology 2008, 19, 375102

[50] F. H. Lin, C. H. Chen, W. T. K. Cheng, T. F. Kuo, Biomaterials 2006, 27, 3333.

[51] N. A. Peppas, J. Z. Hilt, A. Khademhosseini, R. Langer, Adv. Mater. 2006, 18, 1345.

[52] B. V. Slaughter, S. S. Khurshid, O. Z. Fisher, A. Khademhosseini, N. A. Peppas, Adv. Mater. 2009, 21, 3307.

[53] J. K. Tessmar, A. M. Göpferich, Adv. Drug Delivery Rev. 2007, 59, 274. 
[54] J. H. Y. Chung, A. Simmons, L. A. Poole-Warren, Exp. Opin. Drug Delivery 2011, 8, 1 .

[55] A. K. Gaharwar, P. J. Schexnailder, B. P. Kline, G. Schmidt, Acta Biomater. 2011, 7, 568.

[56] Q. Wang, J. Zhang, A. Wang, Carbohydr. Polym. 2009, 78, 731.

[57] K. H. Liu, T. Y. Liu, S. Y. Chen, D. M. Liu, Acta Biomater. 2008, 4, 1038

[58] R. Nanda, A. Sasmal, P. L. Nayak, Carbohydr. Polym. 2011, 83, 988

[59] W. F. Lee, Y. T. Fu, J. Appl. Polym. Sci. 2003, 89, 3652.

[60] W. F. Lee, L. L. Jou, J. Appl. Polym. Sci. 2004, 94, 74.

[61] C. J. Wu, G. Schmidt, Macromol. Rapid Commun. 2009, 30, 1492.

[62] K. Campbell, D. Q. M. Craig, T. McNally, Int. J. Pharm. 2008, 363, 126.

[63] G. R. D. Silva, E. Ayres, R. L. Orefice, S. A. L. Moura, D. C. Cara, A. D. S. Cunha Jr, J. Drug Targeting 2009, 17, 374.

[64] C. J. Wu, A. K. Gaharwar, P. J. Schexnailder, G. Schmidt, Materials 2010, 3, 2986

[65] C. Lu, Y. W. Mai, Compos. Sci. Technol. 2007, 67, 2895.

[66] C. M. Koo, S. O. Kim, I. J. Chung, Macromolecules 2003, 36, 2748.

[67] S. H. Cypes, W. M. Saltzman, E. P. Giannelis, J. Controlled Release 2003, 90, 163

[68] W. F. Lee, Y. C. Chen, J. Appl. Polym. Sci. 2004, 91, 2934

[69] M. Darder, M. Colilla, E. Ruiz-Hitzky, Chem. Mater. 2003, 15, 3774.

[70] J. P. Zheng, C. Z. Wang, X. X. Wang, H. Y. Wang, H. Zhuang, K. D. Yao, React. Funct. Polym. 2007, 67, 780

[71] H. Zhuang, J. P. Zheng, H. Gao, K. De Yao, J. Mater. Sci. Mater. Med. 2007, 18, 951.

[72] X. Wang, Y. Du, J. Luo, Nanotechnology 2008, 19, 065707.

[73] K. S. Katti, D. R. Katti, R. Dash, Biomed. Mater. 2008, 3, 034122.

[74] D. Depan, A. P. Kumar, R. P. Singh, Acta Biomater. 2009, 5, 93.

[75] Q. Yuan, J. Shah, S. Hein, R. Misra, Acta Biomater. 2010, 6, 1140.

[76] S. Hua, H. Yang, W. Wang, A. Wang, Appl. Clay. Sci. 2010, 50, 112.

[77] A. K. Gaharwar, P. J. Schexnailder, Q. Jin, C. J. Wu, G. Schmidt, ACS Appl. Mater. Interfaces 2010, 2, 3119.

[78] M. Chen, D. Q. S. Le, S. Hein, P. Li, J. V. Nygaard, M. Kassem, J. Kjems, F. Besenbacher, C. Bünger, Int. J. Nanomed. 2012, 7, 4285.

[79] J. Lee, S. Shanbhag, N. A. Kotov, J. Mater. Chem. 2006, 16, 3558.

[80] G. Mehta, M. J. Kiel, J. W. Lee, N. Kotov, J. J. Linderman, S. Takayama, Adv. Funct. Mater. 2007, 17, 2701.

[81] Z. Tang, N. A. Kotov, S. Magonov, B. Ozturk, Nat. Mater. 2003, 2, 413.

[82] Z. Tang, Y. Wang, P. Podsiadlo, N. A. Kotov, Adv. Mater. 2006, 18, 3203.

[83] P. J. Schexnailder, A. K. Gaharwar, R. L. Bartlett II, B. L. Seal, G. Schmidt, Macromol. Biosci. 2010, 10, 1416.

[84] K. Haraguchi, T. Takehisa, M. Ebato, Biomacromolecules 2006, 7, 3267.

[85] C. W. Chang, A. van Spreeuwel, C. Zhang, S. Varghese, Soft Matter 2010, 6, 5157

[86] N. Kotobuki, K. Murata, K. Haraguchi, J. Biomed. Mater. Res. 2013, 101A, 537.

[87] G. Nitya, G. T. Nair, U. Mony, K. P. Chennazhi, S. V. Nair, J. Mater. Sci. Mater. Med. 2012, 23, 1749 .

[88] A. Nennemann, S. Kulbach, G. Lagaly, Appl. Clay Sci. 2001, 18, 285

[89] H. B. Alam, D. Burris, J. A. DaCorta, P. Rhee, Mil. Med. 2005, 170, 63.

[90] A. E. Pusateri, A. V. Delgado, E. J. Dick Jr., R. S. Martinez, J. B. Holcomb, K. L. Ryan, J. Trauma Acute Care Surg. 2004, 57, 555.

[91] D. Trabattoni, P. Gatto, A. L. Bartorelli, Int. J. Cardiol. 2012, 156, 53.

[92] A. Sairaku, Y. Nakano, N. Oda, Y. Makita, K. Kajihara, T. Tokuyama, Y. Kihara, J. Interv. Card. Electrophysiol. 2011, 31, 157.
[93] J. W. Carraway, D. Kent, K. Young, A. Cole, R. Friedman, K. R. Ward, Resuscitation 2008, 78, 230.

[94] S. E. Baker, A. M. Sawvel, N. Zheng, G. D. Stucky, Chem. Mater. 2007, 19, 4390

[95] B. J. Carey, P. K. Patra, L. Ci, G. G. Silva, P. M. Ajayan, ACS Nano 2011, 5, 2715.

[96] P. Fratzl, H. S. Gupta, E. P. Paschalis, P. Roschger, J. Mater. Chem. 2004, 14, 2115.

[97] S. Weiner, H. D. Wagner, Annu. Rev. Mater. Sci. 1998, 28, 271.

[98] S. C. Marks, S. N. Popoff, Am. J. Anat. 2005, 183, 1.

[99] K. Akhilesh, J. Patrick, G. Schmidt, in Nanobiomaterials handbook, (Ed: B. Sitharaman), CRC Press, New York, USA 2011.

[100] B. K. G. Theng, in Developments in Clay Science, Vol. 4 (Ed B. K. G. Theng), Elsevier, Amsterdam, Netherlands 2012, 201.

[101] A. K. Gaharwar, P. J. Schexnailder, G. Schmidt, in Nanobiomaterials Handbook, (Ed: B. Sitharaman), Taylor \& Francis, Boca Raton 2011, 1.

[102] K. M. Zia, M. Zuber, M. Barikani, R. Hussain, T. Jamil, S. Anjum, Int. J. Biol. Macromol. 2011, 49, 1131.

[103] J. P. Zheng, P. Li, Y. L. Ma, K. D. Yao, J. Appl. Polym. Sci. 2002, 86, 1189.

[104] T. R. Thatiparti, S. Tammishetti, M. V. Nivasu, J. Biomed. Mater. Res. B 2010, 92B, 111 .

[105] K. Haraguchi, K. Murata, T. Takehisa, Macromolecules 2011, 45, 385.

[106] A. K. Gaharwar, P. Schexnailder, V. Kaul, O. Akkus, D. Zakharov, S. Seifert, G. Schmidt, Adv. Funct. Mater. 2010, 20, 429.

[107] Q.-Z. Chen, S.-L. Liang, J. Wang, G. P. Simon, J. Mech. Behavior Biomed. Mater. 2011, 4, 1805.

[108] R. Chen, C.-A. Wang, Y. Huang, H. Le, Mater. Sci. Eng. C 2008, 28, 218.

[109] X. Wei, S. Raychowdhury, D. D. Jiang, H. Retsos, E. P. Giannelis, Small 2008, 4, 662.

[110] K. Haraguchi, M. Ebato, T. Takehisa, Adv. Mater. 2006, 18, 2250.

[111] I. M. Pereira, S. Carvalho, M. M. Pereira, M. F. Leite, R. L. Orefice, J. Appl. Polym. Sci. 2009, 114, 254.

[112] K. E. Styan, D. J. Martin, L. A. Poole-Warren, J. Biomed. Mater. Res. A 2008, 86A, 271

[113] R. Xu, E. Manias, A. J. Snyder, J. Runt, Macromolecules 2001, 34, 337.

[114] L. Rueda, I. Garcia, T. Palomares, A. Alonso-Varona, I. Mondragon, M. Corcuera, A. Eceiza, J. Biomed. Mater. Res. A 2011, 97A, 480.

[115] S. Dutta, N. Karak, J. P. Saikia, B. K. Konwar, Bioresour. Technol. 2009, 100, 6391.

[116] M. C. Wang, J. J. Lin, H. J. Tseng, S. H. Hsu, ACS Appl. Mater. Interfaces 2012, 4, 338

[117] W. Y. Zhou, B. Guo, M. Liu, R. Liao, A. B. M. Rabie, D. Jia, J Biomed. Mater. Res. A 2010, 93A, 1574.

[118] P. Podsiadlo, A. K. Kaushik, B. S. Shim, A. Agarwal, Z. Tang, A. M. Waas, E. M. Arruda, N. A. Kotov, J. Phys. Chem. B 2008, 112, 14359.

[119] G. F. Perotti, H. S. Barud, Y. Messaddeq, S. J. L. Ribeiro, V. R. L. Constantino, Polymer 2011, 52.

[120] M. Ul-Islam, T. Khan, J. K. Park, Carbohydr. Polym. 2012, 89, 1189.

[121] A. K. Gaharwar, P. J. Schexnailder, A. Dundigalla, J. D. White, C. R. Matos-Perez, J. L. Cloud, S. Seifert, J. J. Wilker, G. Schmidt Macromol. Rapid Commun. 2011, 32, 50

[122] R. Qi, X. Cao, M. Shen, R. Guo, J. Yu, X. Shi, J. Biomater. Sci. Polym. Ed. 2012, 23, 299.

[123] M. Liu, W. Li, J. Rong, C. Zhou, Colloid Polym. Sci. 2012, 290, 895.

[124] M. Zhu, Y. Liu, B. Sun, W. Zhang, X. Liu, H. Yu, Y. Zhang, D. Kuckling, H.-J. P. Adler, Macromol. Rapid Commun. 2006, 27, 1023.

[125] K. Haraguchi, R. Farnworth, A. Ohbayashi, T. Takehisa, Macromolecules 2003, 36, 5732. 
[126] K. Haraguchi, K. Uyama, H. Tanimoto, Macromol. Rapid Commun. 2011, 32, 1253.

[127] M. Fukasawa, T. Sakai, U.-I. Chung, K. Haraguchi, Macromolecules 2010, 43, 4370.

[128] A. K. Gaharwar, C. P. Rivera, C. J. Wu, G. Schmidt, Acta Biomater. 2011, 7, 4139.

[129] C. J. Wu, A. K. Gaharwar, B. K. Chan, G. Schmidt, Macromolecules 2011, 44, 8215

[130] K. Haraguchi, T. Takehisa, Adv. Mater. 2002, 14, 1120.

[131] J. Wang, L. Lin, Q. Cheng, L. Jiang, Angew. Chem. Int. Ed. 2012, 124, 4754.

[132] M. Kokabi, M. Sirousazar, Z. M. Hassan, Eur. Polym. J. 2007, 43, 773.

[133] A. H. Ambre, K. S. Katti, D. R. Katti, J. Nanotechnol. Eng. Med. 2010, 1, 031013.

[134] M. Frydrych, C. Wan, R. Stengler, K. U. O'Kelly, B. Chen, J. Mater. Chem. 2011, 21, 9103.

[135] O. M. Istrate, B. Q. Chen, J. Appl. Polym. Sci. 2012, 125, E102.

[136] C. J. Perez, V. A. Alvarez, I. Mondragon, A. Vazquez, Polym. Int. 2007, 56, 686

[137] K. C. Baker, M. Manitiu, R. Bellair, C. A. Gratopp, H. N. Herkowitz, R. M. Kannan, Acta Biomater. 2011, 7, 3382.

[138] G. Ozkoc, S. Kemaloglu, M. Quaedflieg, Polym. Compos. 2010, 31, 674.

[139] L. J. Hoon, P. T. Gwan, P. H. Sik, L. D. Sung, L. Y. Kwan, Y. S. Chu, N. Jae-Do, Biomaterials 2003, 24, 2773.

[140] V. Krikorian, D. J. Pochan, Chem. Mater. 2003, 15, 4317.

[141] D. Killeen, M. Frydrych, B. Chen, Mater. Sci. Eng. C 2012, 32.

[142] S. Sinha Ray, M. Okamoto, Prog. Polym. Sci. 2003, 28, 1539.

[143] T. Fornes, D. Paul, Polymer 2003, 44, 4993.

[144] K. Rezwan, Q. Z. Chen, J. J. Blaker, A. R. Boccaccini, Biomaterials 2006, 27, 3413.

[145] K. Haraguchi, Y. Xu, G. Li, Macromol. Rapid Commun. 2010, 31, 718.

[146] K. Haraguchi, J. Stem Cells Regen. Med. 2012, 8, 2.

[147] S. Miyazaki, H. Endo, T. Karino, K. Haraguchi, M. Shibayama, Macromolecules 2007, 40, 4287.
[148] Q. Wang, J. L. Mynar, M. Yoshida, E. Lee, M. Lee, K. Okuro, K. Kinbara, T. Aida, Nature 2010, 463, 339.

[149] J. Wang, L. Lin, Q. Cheng, L. Jiang, Angew. Chem. Int. Ed. 2012, 51, 4676.

[150] N. Olmo, M. A. Lizarbe, J. G. Gavilanes, Biomaterials 1987, 8, 67.

[151] M. A. Lizarbe, N. Olmo, J. G. Gavilanes, Biomaterials 1987, 8, 35.

[152] J. I. Herrera, N. Olmo, J. Turnay, A. Sicilia, A. Bascones, J. G. Gavilanes, M. A. Lizarbe, Biomaterials 1995, 16, 625.

[153] P. Popryadukhin, I. Dobrovolskaya, V. Yudin, E. Ivan'kova, A. Smolyaninov, N. Smirnova, Cell Tissue Biol. 2012, 6, 82.

[154] P.-R. Li, J.-C. Wei, Y.-F. Chiu, H.-L. Su, F.-C. Peng, J.-J. Lin, ACS Appl. Mater. Interfaces 2010, 2, 1608.

[155] M. Baek, S. J. Choi, J. Nanomater. 2012, 2012, 7.

[156] M. Baek, J. A. Lee, S. J. Choi, Mol. Cell. Toxicol. 2012, 8, 95

[157] A. K. Sharma, B. Schmidt, H. Frandsen, N. R. Jacobsen, E. H. Larsen, M.-L. Binderup, Mutat. Res., Genet. Toxicol. Environ. Mutagen. 2010, 700, 18.

[158] H.-K. Han, Y.-C. Lee, M.-Y. Lee, A. J. Patil, H.-J. Shin, ACS Appl. Mater. Interfaces 2011, 3, 2564.

[159] N. K. Verma, E. Moore, W. Blau, Y. Volkov, P. R. Babu, J. Nanopart. Res. 2012, 14, 1.

[160] S. Lordan, J. E. Kennedy, C. L. Higginbotham, J. Appl. Toxicol. 2011, 31, 27.

[161] S. Lordan, C. L. Higginbotham, Cell Biol. Int. 2012, 36, 57.

[162] L. Reijnders, J. Mater. Sci. 2012, 47, 5061.

[163] T. Takezawa, Y. Mori, K. Yoshizato, Nat. Biotechnol. 1990, 8, 854.

[164] Y. Akiyama, A. Kikuchi, M. Yamato, T. Okano, Langmuir 2004, 20, 5506.

[165] D. Liu, T. Wang, X. Liu, Z. Tong, Biomed. Mater. 2012, 7, 055008.

[166] A. A. Haroun, A. Gamal-Eldeen, D. R. K. Harding, J. Mater. Sci. Mater. Med. 2009, 20, 2527.

[167] H. M. Lewkowitz-Shpuntoff, M. C. Wen, A. Singh, N. Brenner, R. Gambino, N. Pernodet, R. Isseroff, M. Rafailovich, J. Sokolov, Biomaterials 2009, 30, 8 .

[168] A. J. Mieszawska, J. G. Llamas, C. A. Vaiana, M. P. Kadakia, R. R. Naik, D. L. Kaplan, Acta Biomater. 2011, 7, 3036.

[169] A. Ambre, K. S. Katti, D. R. Katti, Mater. Sci. Eng. C 2011, 31, 1017. 